\title{
Skylon Aerodynamics and SABRE Plumes
}

\author{
Unmeel Mehta $^{*}$, Michael Aftosmis $^{\dagger}$, Jeffrey Bowles ${ }^{\ddagger}$, and Shishir Pandya ${ }^{\S}$ \\ NASA Ames Research Center, Moffett Field, California 94035, USA
}

\begin{abstract}
An independent partial assessment is provided of the technical viability of the Skylon aerospace plane concept, developed by Reaction Engines Limited (REL). The objectives are to verify REL's engineering estimates of airframe aerodynamics during powered flight and to assess the impact of Synergetic Air-Breathing Rocket Engine (SABRE) plumes on the aft fuselage. Pressure lift and drag coefficients derived from simulations conducted with Euler equations for unpowered flight compare very well with those REL computed with engineering methods. The REL coefficients for powered flight are increasingly less acceptable as the freestream Mach number is increased beyond 8.5, because the engineering estimates did not account for the increasing favorable (in terms of drag and lift coefficients) effect of underexpanded rocket engine plumes on the aft fuselage. At Mach numbers greater than 8.5, the thermal environment around the aft fuselage is a known unknown-a potential design and/or performance risk issue. The adverse effects of shock waves on the aft fuselage and plumeinduced flow separation are other potential risks. The development of an operational reusable launcher from the Skylon concept necessitates the judicious use of a combination of engineering methods, advanced methods based on required physics or analytical fidelity, test data, and independent assessments.
\end{abstract}

\section{Nomenclature}

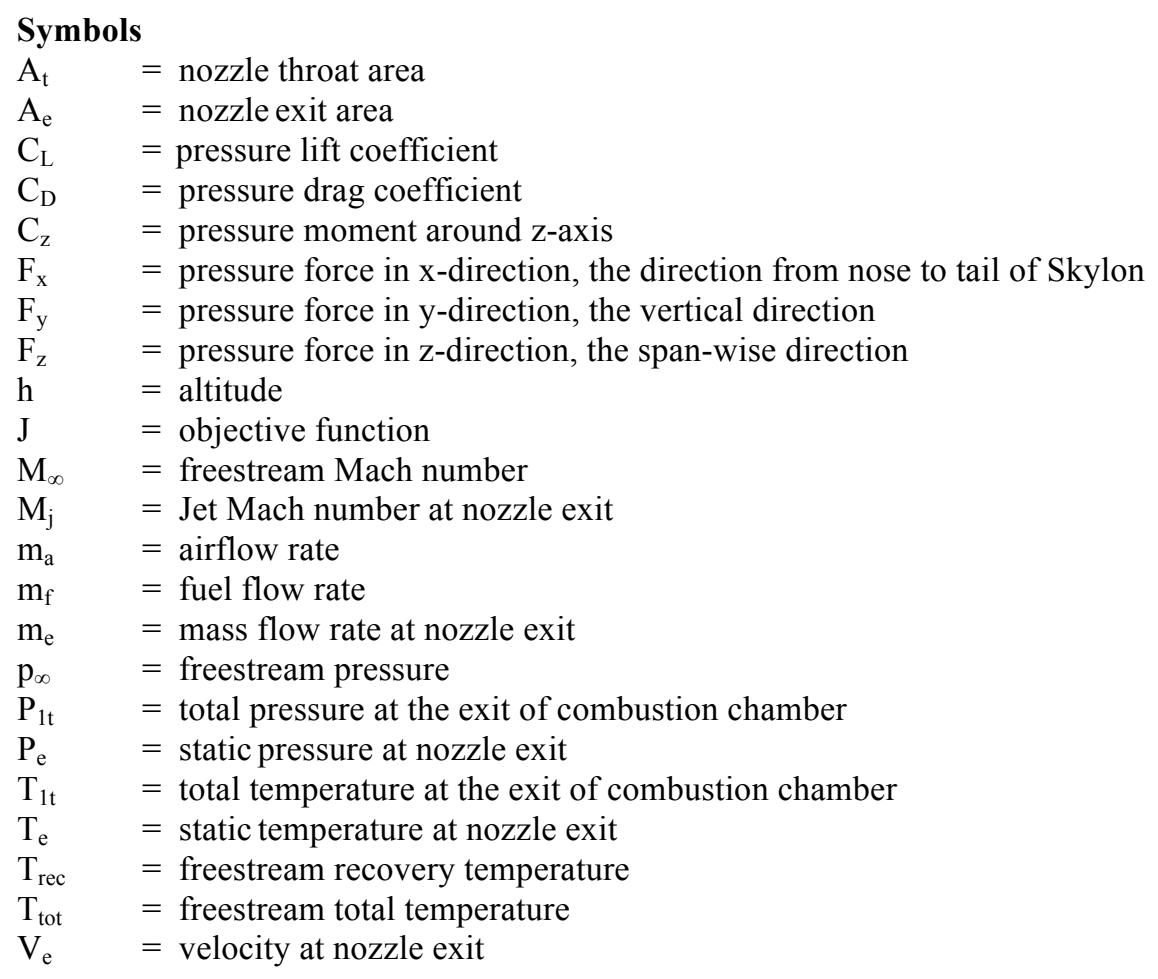

\footnotetext{
*Aerospace Engineer, NASA Advanced Supercomputing Division, Unmeel.B.Mehta@nasa.gov, Associate Fellow, AIAA.

†Aerospace Engineer, Applied Modeling and Simulation Branch, Michael.Aftosmis@nasa.gov, Associate Fellow, AIAA.

¥Aerospace Engineer, System Analysis Branch, Jeffrey.V.Bowles@nasa.gov.

§Aerospace Engineer, Fundamental Modeling and Simulation Branch, Shishir.Pandya@nasa.gov, Senior Member, AIAA.
} 
$\alpha_{\mathrm{f}} \quad=$ foreplane angle of attack

$\alpha_{\mathrm{v}} \quad=$ vehicle angle of attack

$\gamma_{j} \quad=$ ratio of specific heat $(\gamma)$ at the nozzle exit

\section{Acronyms}

ACES = Air Collection and Enrichment System

$\mathrm{CAD}=$ Computer-Aided Design

HOTOL $=$ HOrizontal Take-Off and Landing

LEO $=$ Low-Earth Orbit

NASP $=$ National Aero-Space Plane

PIFS = Plume Induced Flow Separation

ROLS $=$ Recoverable Orbital Launch System

SABRE $=$ Synergetic Air-Breathing Rocket Engine

\section{Abbreviations}

$\mathrm{ARCC}=$ Air-Breathing/Rocket Combined Cycle

Cart3D $=$ Cartesian 3 Dimensions

CFD = Computational Fluid Dynamics

$\mathrm{ELV}=$ Expendable Launch Vehicle

REL $=$ Reaction Engines Limited

RLV $=$ Reusable Launch Vehicle

RLS $=$ Reusable Launch System

SSME = Space Shuttle Main Engine

SSTO $=$ Single Stage To Orbit

TBCC = Turbine-Based Combined Cycle

TSTO $=$ Two Stage To Orbit

US $=$ United States

\section{Units}

$\operatorname{deg}=$ degree

$\mathrm{ft} \quad=$ feet

$\mathrm{K}=$ Kelvin

$\mathrm{km} \quad=$ kilometer

$\mathrm{m} \quad=$ meter

$\mathrm{M} \quad=$ million

$\mathrm{mm}=$ millimeter

$\mathrm{N} \quad=$ Newton

$\mathrm{Pa} \quad=$ Pascal

psi $=$ pound per square inch

$\mathrm{R} \quad=$ Rankine

$\mathrm{s} \quad=$ second

\section{Rationale and Objective}

Serious efforts began in 1958 to develop a reusable launch vehicle (RLV) for transportation to low Earth orbit (LEO) with the start of the Aerospaceplane program. ${ }^{1,2}$ In 1970, when the U.S. Space Shuttle Phase B award began, NASA and contractors were generally unanimous in considering a two stage to orbit (TSTO) reusable launch system (RLS) powered with rocket engines as the system of choice. ${ }^{3,4}$ However, the design was changed to fit the budget and the full reusability requirement was dropped. ${ }^{4,5}$ Subsequently, substantial efforts to develop reusable launchers were pursued in endeavors such as the National Aero-Space Plane (NASP), Sänger II, X-33/VentureStar, and Skylon. Almost all RLV and RLS efforts were terminated, the reasons for which are highlighted below. Only the Skylon endeavor is ongoing, principally because the conceptual design of Skylon incorporates potential breakthrough propulsive advances. Those failures and advances provide the rationale for the assessment effort undertaken here. The specific motivation and objectives for this work are stated at the end of this section. 
The Aerospaceplane program (1958-1964) was initiated to develop a single-stage-to-orbit (SSTO) aerospace plane powered by an air-breathing engine. Numerous launch configurations were investigated. The program evolved into the Recoverable Orbital Launch System (ROLS), an SSTO vehicle. ${ }^{2}$ The ROLS had a complicated and badly conceived $^{6}$ propulsion system - a Liquid Air Collection Engine (LACE) System, which was later renamed the Air Collection and Enrichment System (ACES). When the feasibility of the SSTO design became uncertain, the focus shifted to TSTO system concepts. The selected TSTO system corresponded closely to Sänger II. ${ }^{1}$ The program technology effort focused on the construction of a scramjet engine to be launched on top of a missile. ${ }^{7}$ The United States Air Force Scientific Advisory Board condemned the program and asserted the following: "The so-called Aerospaceplane program has had such an erratic history, has involved so many clearly infeasible factors, ... It is also recommended that the Air Force increase the vigilance that no new program achieves such a difficult position." 7

The National Aero-Space Plane (NASP) program (1986-1995) was planned to build and flight-test a manned experimental vehicle, the X-30, to validate technologies. The disciplines of propulsion, structures, and aerodynamics were highly coupled. New technologies related to air-breathing scramjets and combined-cycle engines, new materials, a new design process, and advances in computational fluid dynamics (CFD) for credible simulations were required. Although tremendous advances were made in technology, its overall goal, an SSTO RLV for space access, was very difficult to achieve. As designed, the X-30, with an arbitrary takeoff gross weight limit, was unable to achieve the SSTO goal, after approximately 2.86 billion dollars ${ }^{8}$ were expended.

The X-30's integrated air-breathing engine was to operate in three modes: low speed $\left(\mathrm{M}_{\infty}=0\right.$ to $\left.\sim 3\right)$, ramjet $\left(\mathrm{M}_{\infty}=\sim 3\right.$ to $\left.\sim 6\right)$, and scramjet $\left(\mathrm{M}_{\infty}=\sim 6\right.$ to $\left.\sim 16\right)$. Rocket propulsion was used to achieve orbit. External burning was used to reduce the drag created by the X-30's nozzle at lower speeds. Engine tests demonstrated that the engine design looked promising at high speeds, but it did not produce sufficient thrust at lower speed. ${ }^{8}$ The proposed integrated propulsion system presented unprecedented challenges. "Perhaps the highest technical risk in the program is the ability to quantify the characteristics of the scramjet and its flowpath integration into the airplane." ${ }^{9}$ Whether the goal of SSTO was worth pursuing on its own merit was also questioned. ${ }^{8}$ The RAND Corporation also believed that a TSTO concept close to Sänger II should be a strong contender for the NASP program. ${ }^{1}$ Subsequently, additional efforts were conducted to develop a TSTO RLS with air-breathing propulsion on the first stage. $^{10,11,12,13,14,15,16,17,18}$

A way to increase the Mach range of air-breathing propulsion is to use a turbine-based combination cycle engine (TBCC), which is designed either with a turbine or turbo-ramjet engine (for example, the PW-J58 engine) plus a dual-mode ramjet (or ramjet-scramjet) engine. Ideally, a dual-mode ramjet engine would nominally start in ramjet mode at $\mathrm{M}_{\infty}=3$, then transition from ramjet mode to scramjet mode around $\mathrm{M}_{\infty}=7$, and finally perform in scramjet mode until $\mathrm{M}_{\infty} \sim 16$. The ramjet and scramjet technologies are relatively easier than the dual-mode technology.

Over the last 55-plus years, there has been a lack of progress in developing an operational dual-mode ramjet engine across a wide freestream Mach number range. Likewise, the aforementioned TBCC engine has yet to be demonstrated in a continuous operation over a meaningful Mach range.

Without a ground-based test facility for testing a dual-mode ramjet or a TBCC engine across a Mach number range of interest during a single test run, the development effort for such engines is difficult. The size of the tested engine and the test environment need to be appropriate. The absence of long-duration, clean-air, true-enthalpy, highMach-number testing capability is a serious issue for developing high-Mach-number scramjet technology. For example, such a capability is required to ascertain structural response to scramjet aero-thermal environments. Thus, the development of an operational dual-mode scramjet that operates from $\mathrm{M}_{\infty} \sim 3$ to $\sim 16$ is extremely difficult compared to the task of extending the maximum operational Mach number of turbine engines from $\mathrm{M}_{\infty} \sim 2.5$ to $~$ 5.5 with pre-compressor cooling. The use of a turbine engine operating up to $\mathrm{M}_{\infty} \sim 5.5$ allows the start of a dualmode scramjet at $\mathrm{M}_{\infty} \sim 5$ in a TBCC engine.

The integration of a turbine engine with a dual-mode ramjet engine can be avoided if different propulsion systems are in separate vehicles. A four-stage RLS could be used to launch small satellites. ${ }^{19}$ A subsonic carrier aircraft carries a two-stage system and launches it. This system consists of the second stage, a supersonic aircraft, and the third stage, a hypersonic aircraft. The third stage is in tandem with the second stage. The hypersonic aircraft carries the fourth stage internally. This stage is powered with a rocket engine and carries the payload. All stages are recovered for future use. Another approach is to launch an expandable, rocket-powered multi-staged system at a subsonic Mach number from an aircraft. ${ }^{20,21,22}$ Both of these approaches have the potential to reduce current launch costs, but they are not satisfactory for commercializing LEO.

Sänger II was only a lead reference concept for the German Hypersonic Technology Program (1988-1993) ${ }^{23}$ It was designed as a TSTO RLS concept because of a firm conviction that SSTO RVLs were not practical. The first stage and the second stage were, respectively, powered by a turbo-ramjet combined cycle engine and rocket engines. 
The first stage was designed to cruise and could be evolved into a hypersonic aircraft. The second stage was a winged vehicle. Conceptually, it was staged at $\mathrm{M}_{\infty}=6.6$. The Hypersonic Technology Program also included the development and test of a subscale flight demonstrator to validate the design and propulsion system of the first stage. A concentric propulsion system with the turbojet in the middle and the ramjet surrounding it (a coaxial turbo-ramjet engine) was chosen. ${ }^{24,25}$ In 1994, the Sänger II technology and development effort was cancelled, because it would have been very costly and because the first-generation system would reduce the launch cost only between 10 to $30 \%$ below that of the Arian 5 ELV. ${ }^{26}$

The X-33 program (1996-2001) was to pave the way to VentureStar, an SSTO RLV. The X-33 reusable launcher was a sub-scale, unmanned technology demonstrator powered with rocket engines. It was designed to achieve $\mathrm{M}_{\infty} \sim 13$, and to land horizontally like an airplane. The X-33 program experienced difficulties achieving its goals primarily because realistic cost estimates, timely acquisition and risk management plans, and adequate and realistic performance goals were not developed. ${ }^{27}$ During its life 1.27 billion dollars were expended. ${ }^{28}$

Since SSTO RLVs were not feasible with rocket engines, the basic idea for the SSTO HOrizontal Take-Off and Landing (HOTOL) vehicle (1982-1989) was to augment rocket engine performance using the atmosphere instead of starting with an air-breathing engine, and then find some way to add a rocket engine for the latter part of the flight. ${ }^{29}$ This approach was used to design the HOTOL propulsion system-the Rolls Royce RB545 engine-which was a combined cycle pre-cooled engine. ${ }^{30}$

The conceptual, unpiloted, reusable Skylon aerospace plane-an SSTO RLV, which can be used as a reusable first stage of a TSTO launch system ${ }^{31}-(1989-$ present) evolved from HOTOL. For this concept, various propulsion concepts-hydrogen/oxygen rockets, scramjets, turbojets, turborockets, and Liquid Air Cycle Engines-were considered. ${ }^{32}$ The conceptual Synergistic Air-breathing Rocket Engine (SABRE) was specifically designed to combine some of the best features of the considered concepts while simultaneously overcoming their faults. This combined-cycle engine (Fig. 1) is a highly innovative concept-the engine operates in either the turbine, turboramjet, or rocket mode.

The foremost enabling technology in SABRE is the demonstrated heat exchanger technology. ${ }^{33,34,35}$ This technology is essential in order to significantly expand the operational envelope of conventional turbine engines by pre-cooling hot ram-compressed air at high speeds. The operation of turbine engines at up to $\mathrm{M}_{\infty} \sim 5.5$ and a combination of air-breathing and rocket propulsions as accomplished in SABRE will lead to a revolutionary change in the mode of propulsion for space transportation. Only by revolutionary changes in modes of propulsion progress in transportation has been made. ${ }^{20,36,37}$

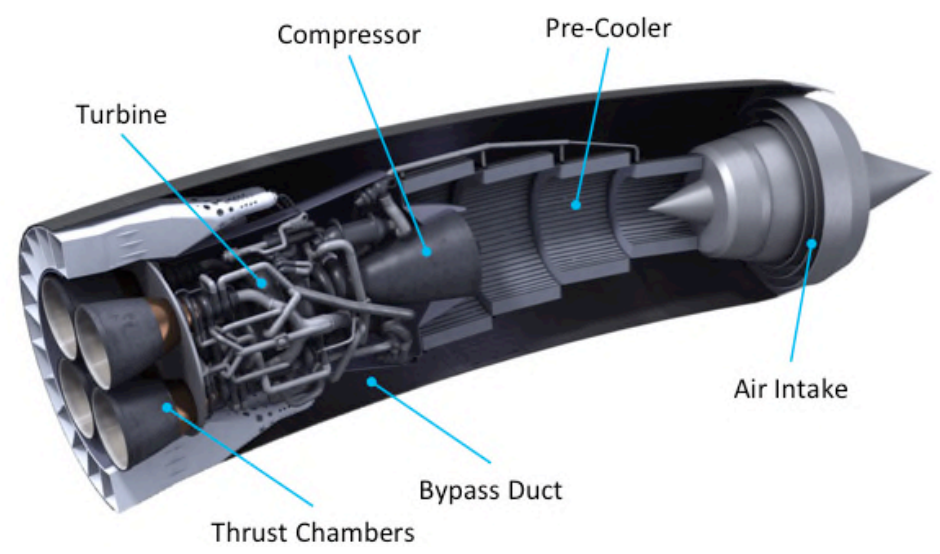

Figure 1. Synergistic Air-breathing Rocket Engine (SABRE).

(Courtesy of Reaction Engines Limited)

A viable LEO transportation vehicle or system manifests the following figures of merit: ${ }^{36}$ affordability and reliability for exploration, security, and commerce; safety for humans and critical cargo; operational responsiveness for security and emergency human spaceflights; and sustainability for human exploration. The design of this entity is based on the following factors: reference mission, vehicle or system configuration, propulsion, materials and structures, flight controls, operational concept, environment impact, the degree of reusability, integrated health management, and operational and maintenance infrastructures. A revolutionary propulsion system, a high degree of reusability, aircraft-like operations, mature design, and airline industry practices significantly reduce the Earth to LEO transportation cost per kilogram of payload transported - a necessary condition to increase demand for civil and commercial use of launch vehicles. Greatly reduced costs lead to commercialization of LEO. 
Can the Skylon concept lead to a viable transport to LEO? The motivation here is to partially address that question with an independent assessment. We address two aspects of this assessment with a level of physics fidelity higher than that feasible with engineering methods.

Our objectives are: (a) to determine with computational fluid dynamics (CFD) the Skylon airframe aerodynamics during powered flight and to compare these results with those developed by REL with engineering methods for the Skylon design, and (b) to assess the impact of SABRE plumes. The aft fuselage is most likely to be engulfed by the plumes at moderate and high Mach numbers, because the SABRE engines are mounted on the wingtips with about one-third of the Skylon fuselage being downstream of these engines (Fig. 2). Potential adverse effects of plumes are identified. The value-added assessment presented here includes issues and associated potential design risks not addressed with engineering methods and how to address them. Previous independent investigations did not address these objectives. $38,39,40,41,42,43$

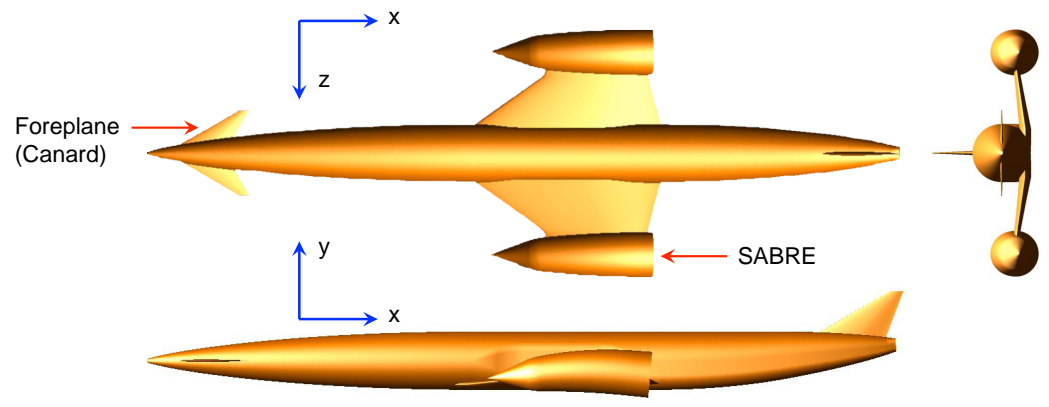

Figure 2. Skylon D1.5a with inlets closed.

\section{Analysis Approach}

Reaction Engines Limited provided computer-aided design (CAD) data defining Skylon D1.5a, relevant design data at flight conditions of interest, and the corresponding aerodynamic data to compare with those determined in the present study. A CFD analysis was conducted at the provided flight conditions. The fluid is considered inviscid and non-radiative. Simulations are performed using the Cart3D package developed at NASA Ames Research Center. The credibility of the simulations is established through computational mesh refinement. Although air is used as the simulant fluid, care is taken to match nozzle exit pressure and thrust.

\section{A. Cart3D Simulation Method}

The Cart3D simulation package uses a Cartesian cut-cell approach ${ }^{44,45}$ in which the Euler equations for inviscid perfect-gas flow are discretized on a multilevel Cartesian mesh with embedded boundaries. The mesh consists of regular Cartesian hexahedra everywhere, except for a layer of body-intersecting cells. The spatial discretization uses a second-order accurate finite volume method with a weak imposition of boundary conditions. The upwind fluxvector splitting approach of van Leer is used. ${ }^{46}$ Although the mesh consists of nested Cartesian cells, it is viewed as an unstructured collection of control volumes, making the approach well suited for solution-adaptive mesh refinement. Steady-state flow solutions are obtained using a five-stage Runge-Kutta scheme with local time stepping and multigridding. Domain decomposition via space-filling curves permits parallel computation. Further details are available in Refs. 45, 47, 48, 49, and 50. Freestream air properties are based on the 1976 U.S. Standard Atmosphere. ${ }^{51}$

Adjoint error-estimates are used to drive mesh adaptation to control and minimize discretization error in the computed simulations through local grid refinement. This procedure is based on an earlier approach for the formulation of reliable local error estimates ${ }^{52}$ and the approach for incremental refinement of nested Cartesian cutcell meshes. ${ }^{53}$ The level of discretization error in engineering objectives, typically integral outputs such as coefficients of lift and drag, is reliably and accurately predicted in an affordable and fully automatic manner, ${ }^{50,54}$ avoiding manual distribution of cells based on "best practices." This approach not only estimates error in output due to discretization, but also provides a cell-wise error indicator to guide mesh refinement.

In the simulations described here, a combination of airframe lift and drag coefficients is used as the adaptation functional and the desired error tolerance is specified. Once the local contributions to errors in these outputs are known, this information guides adaptive cell refinement to reduce the error to below a specified tolerance. Cells introducing large uncertainties are refined to minimize functional error. The flow simulation is then recomputed on 
the adapted mesh. Several adaptation cycles later, a grid-converged simulation is obtained on a mesh specifically tailored to each flight condition. An important feature of the method is that each simulation is automatically accompanied by convergence histories of both aerodynamic forces and adjoint error-estimates as a function of mesh refinement, establishing the credibility of computed forces.

\section{B. Propulsive Boundary Conditions}

The SABRE inlet provides air to both the turbine and ramjet engines. This inlet is closed during rocket engine operation. Both the turbine and rocket engines use the same nozzle to expel the combustor chamber fluid. Nozzle profiles similar to those of the Space Shuttle Main Engine (SSME) are assumed. Nozzles are not gimbaled. The flow coming out from the ramjet engine in the bypass duct (Fig. 1) is accounted for separately. The fluid flow exiting SABRE 4 is modeled to provide the computational boundary conditions.

When either the turbine or rocket engine is in operation, propulsive boundary conditions are applied downstream of nozzle throat but upstream of nozzle exit at the power interface in Fig. 3 . The nacelle plume simulation is much more realistic when the propulsive boundary conditions are placed near the nozzle throat than when they are placed at the nozzle exit. When the rocket mode is on, the slip-flow boundary condition is applied along the exit face of the bypass duct.

Because the fluid passing through the nozzle exit is not a perfect gas, the flow conditions at the nozzle exit are converted to those corresponding to cold air (perfect gas) using exit dynamic pressure ratio $\left(\gamma_{j} \mathrm{M}_{\mathrm{j}}^{2}\right)_{\text {real }} /\left(\gamma_{\mathrm{j}} \mathrm{M}_{\mathrm{j}}^{2}\right)_{\text {perfect }}$, where $\gamma$ is the ratio of specific heats. That is, the exit Mach number is adjusted to correspond to that for cold air $\gamma$, while maintaining the "perfect" dynamic pressure that is the same as the "real" nozzle exhaust dynamic pressure. The engine thrust with cold air is essentially the same as that with real exhaust. This scaling also approximately maintains in cold air simulations the size and shape of the plume and the distance and location of plume penetration in the freestream fluid. ${ }^{55,56}$

The relevant flow conditions at the nozzle power interface are determined in two steps: (1) Flow conditions are calculated at the nozzle exit by solving quasi-one-dimensional mass, momentum, and energy equations from the nozzle throat to the nozzle exit. The nozzle throat and exit areas, combustor chamber pressure, and fuel and oxidizer flow rates are used. Mole fractions are frozen at their values at the throat. Velocity, pressure, density, Mach number, $\gamma_{\mathrm{j}}$, gross thrust, and specific impulse are determined at the nozzle exit. (2) Using the real values of $\gamma_{\mathrm{j}}$ and $\mathrm{M}_{\mathrm{j},}$, the nozzle exit Mach number for $\left(\gamma_{\mathrm{j}}\right)_{\text {perfect }}(=1.4)$ is determined. Subsequently, flow conditions are obtained at the power interface (Figs. 3 and 4) using isentropic flow relations. These conditions are used as the power interface boundary conditions.

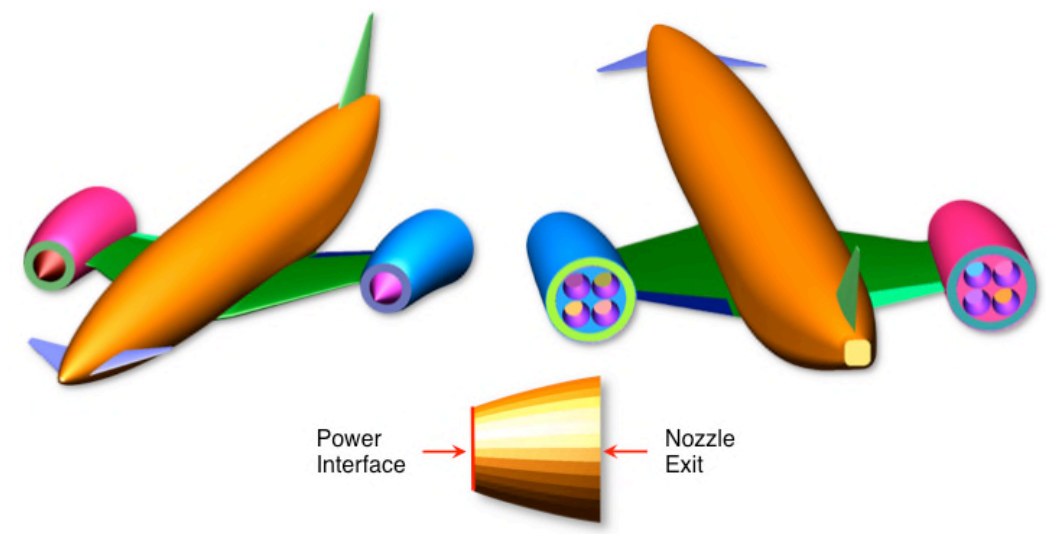

Figure 3. The SABRE 4/Ames engine in turbo-ramjet mode of operation and the nozzle power interface.

During the rocket mode of operation of SABRE 4, steps (1) and (2) lead to the gross thrust that is $104.2 \%$ of the value that REL provided. These thrust values are based on one-dimensional analyses. The computed gross thrust values from three-dimensional simulations are $105 \%$ of the REL value. Please note that the technical specification lists gross thrust to be approximately $2 \mathrm{MN}$ per nacelle in the Mach number range from 5.2 to $27.8 .^{57}$

In the case of turbo-ramjet operation, the assumption is made that the combustion chamber is directly connected to the nozzle. An air-rocket analysis is conducted (Fig. 4). The fuel flow rate $\left(\mathrm{m}_{\mathrm{f}}\right)$, airflow rate $\left(\mathrm{m}_{\mathrm{a}}\right)$, total pressure $\left(\mathrm{P}_{1 t}\right)$, and total temperature $\left(\mathrm{T}_{1 t}\right)$ are known at the exit of the combustion chamber. From these quantities, thermoequilibrium total enthalpy and total entropy are obtained. The nozzle throat conditions are determined, assuming an isentropic process to the throat pressure from the combustor chamber exit, such that the Mach number at throat is 
unity. The throat area $\left(\mathrm{A}_{t}\right)$ and exit area $\left(\mathrm{A}_{\mathrm{e}}\right)$ are also known. (The former is different from that for the rocket engine and the latter is the same as that for the rocket engine.) Subsequently, the aforementioned step (1) is applied up to the power interface and the isentropic process is used to obtain nozzle exit conditions. (If step (1) were followed all the way to the nozzle exit, the thrust per nozzle would have been $107.1 \%$ of the value obtained when the isentropic process is used from power face to the exit.) Step (2) is then followed.

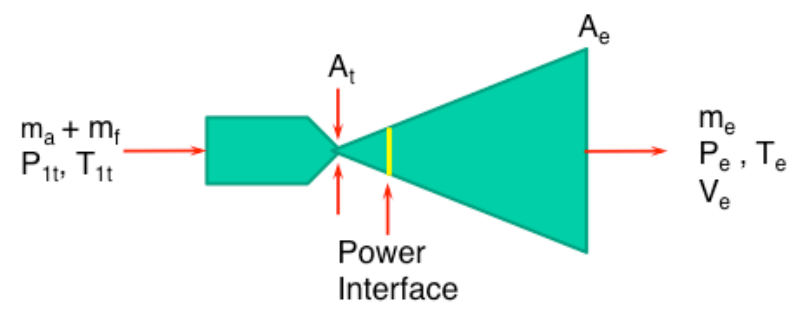

Figure 4. Air rocket analysis.

The performance of the ramjet engine and the design of the bypass duct (Fig. 1) were unavailable for SABRE 4. The one-dimensional ramjet engine exit boundary conditions for the scaled SABRE 3 are assumed for the SABRE 4/Ames engine and applied at the exit face of the bypass duct. The key difference between the SABRE 4 and SABRE 4/Ames engines is that the bypass duct exit area of the latter engine is $70.6 \%$ of that of the former engine. Due to the treatment of the turbine engine as an air-rocket engine and the use of a smaller duct area, the gross thrust of the SABRE 4/Ames engine is $87.5 \%$ less than that of the scaled SABRE 3 engine. In the Mach number range from 0 to 5.5 , the technical specification lists approximate gross thrust to be 0.8 to $2 \mathrm{MN}$ per nacelle. ${ }^{57}$ Note that the assumption made at the boundary has no consequence on airframe aerodynamic forces, the focus of this study. The nacelle plume shape could be somewhat different. But that is of negligible consequence at $\mathrm{M}_{\infty}=3.508$, the airbreathing powered flight condition studied.

\section{Simulation Credibility}

The objective is to obtain aerodynamic forces such that they are independent of the computational mesh. The verification of derived aerodynamic forces for every flight condition is conducted with adjoint-based mesh adaptation using an integrated force objective function, $J=C_{L}+C_{D}$. Three examples of adaptation are presented: (i) $\mathrm{M}_{\infty}=5.0$ unpowered flight at $\alpha_{\mathrm{v}}=\alpha_{\mathrm{f}}=10^{\circ}$ with inlet closed; (ii) $\mathrm{M}_{\infty}=3.508$ powered flight at $\alpha_{\mathrm{v}}=4.521^{\circ}, \alpha_{\mathrm{f}}=$ $-0.294^{\circ}$; and (iii) $\mathrm{M}_{\infty}=12.189$ rocket-powered flight at $\alpha_{\mathrm{v}}=\alpha_{\mathrm{f}}=7.512^{\circ}$. Herein, $\alpha_{\mathrm{v}}$ and $\alpha_{\mathrm{f}}$ are, respectively, vehicle angle of attack and foreplane (canard) angle of attack.

Figure 5 presents, for example (i), the convergence of the aerodynamic forces and moment, the functional, and the remaining error estimates. Excellent mesh convergence for the integrated forces and flow field is observed. There are virtually no changes in forces and moment over the last two adjoint-driven adaptations [Fig. 5(a)]. Figure 5 (b) shows the value of the functional (J) on each mesh adaptation. Adjoint error-estimates are very well behaved. At the last adaptation, $22 \mathrm{M}$ cells are used.

A very high resolution of the flow field is achieved with mesh adaptation. Figure 6 presents the cell distribution near Skylon and the pressure isobars on its surface and in a horizontal plane, vertical plane, and cross plane, on the top, middle, and bottom of this figure, respectively. Regions with high-pressure gradients are observed. The cell density is high in regions where rapid changes in flow properties occur over short distances, affecting aerodynamic forces. For example, the simulation of the inlet cone shocks and the nacelle-wing corner shocks require a high concentration of cells (Fig. 6, bottom). Figure 7 presents isobars on the top and lower surfaces of Skylon, showing complex shock-shock interactions.

Figure 8 presents, for case (ii), the convergence of the aerodynamic forces, the magnitude of update to the functional, and the adjoint estimate of error. Again, there are virtually no changes in forces over the last two adjointdriven adaptations [Figure 8(a)]. At the last adaptation, 26 million cells are used. Figure 8(b) shows that the estimate of error and the magnitude of update to the function are in the asymptotic range. Figure 9 shows the cell distribution in the symmetry plane.

Figure 10(a) shows the history of the force coefficients as the number of cells is increased for a rocket-powered flight at $\mathrm{M}_{\infty}=12.189$. The force coefficients nearly achieve their asymptotic values when there are $8 \mathrm{M}$ cells. That observation is also valid for cases (i) and (ii). Figure 10(b) shows the convergence of the adjoint estimate of error bound and the update to the functional as functions of the number of cells. Figure 11 shows the cell distribution and pressure field in the symmetry plane and the surface pressure field. 


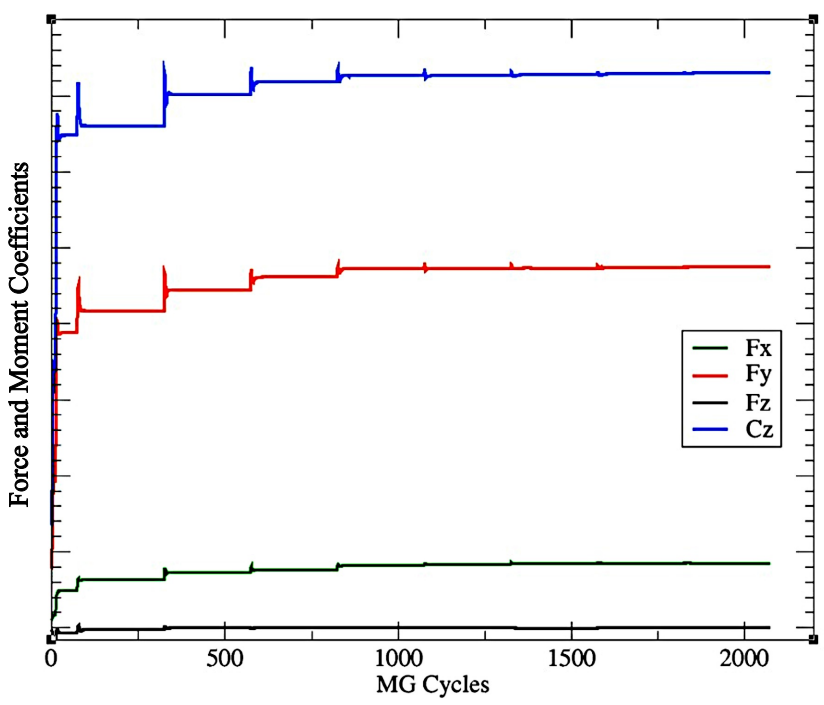

(a) Pressure forces and moment convergence and multi-grid (MG) cycles

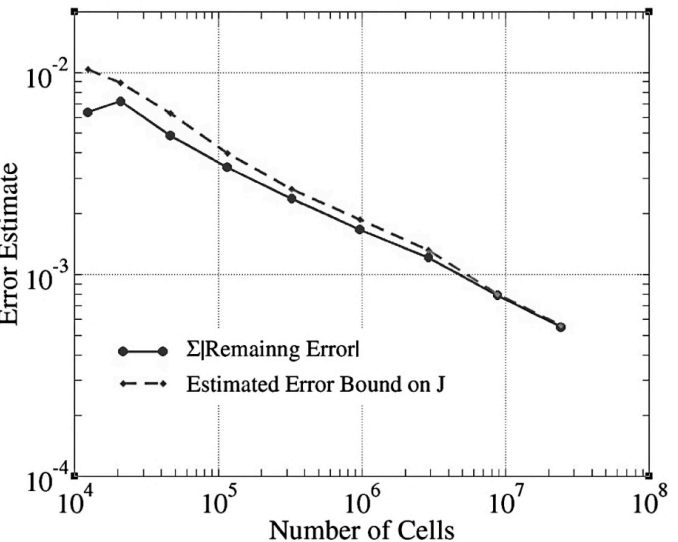

(b) Convergence of adjoint-based error estimates

Figure 5. Forces, the pitching moment, and mesh convergence at $\mathrm{M}_{\infty}=5.0$ and $\alpha=10^{\circ}$ with engine inlets closed.
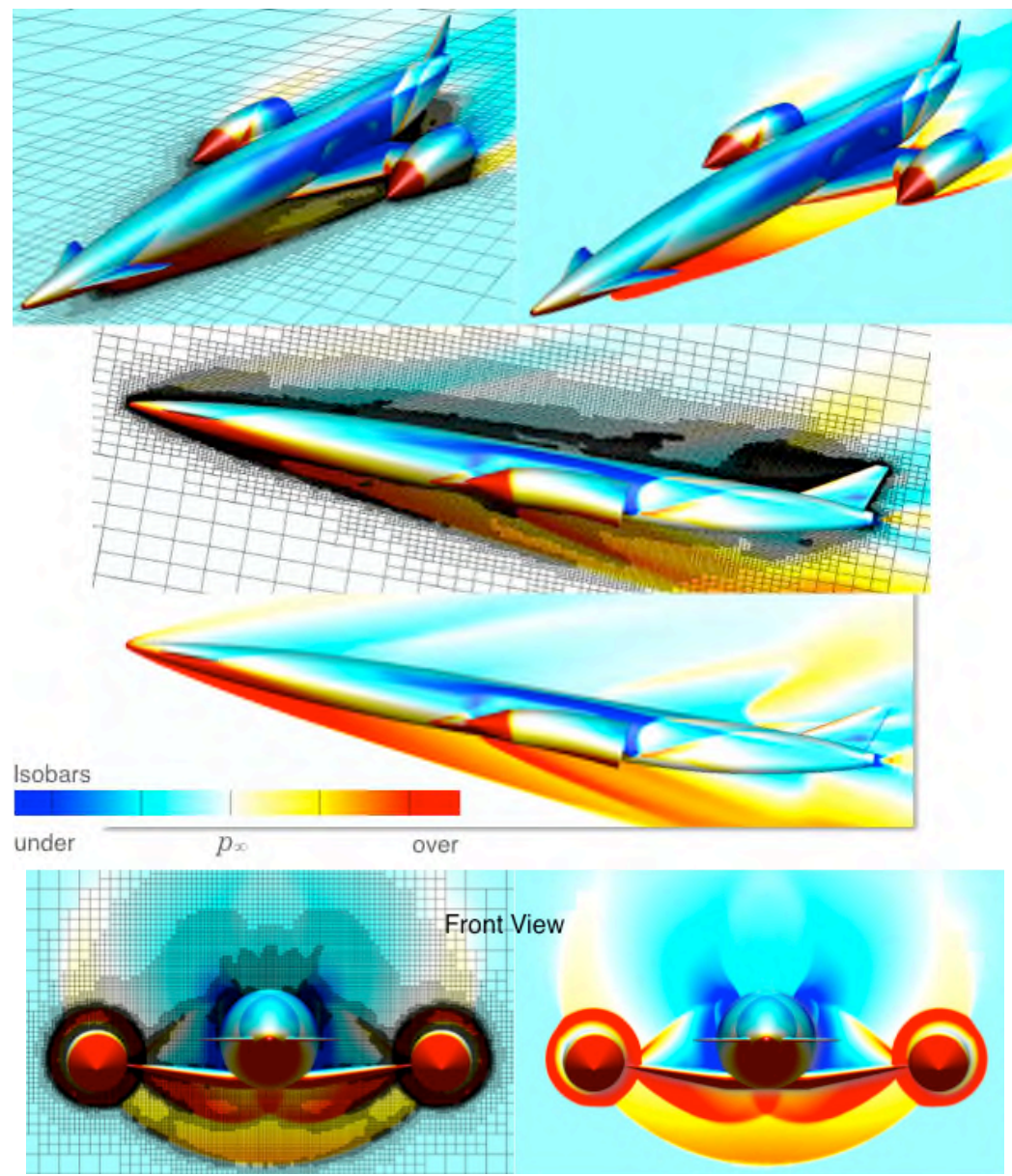

Figure 6. Isobars on the surface and in a horizontal plane (top), symmetry plane (center), and cross plane (bottom) with cells at $\mathrm{M}_{\infty}=5.0$ and $\alpha=10^{\circ}$ for unpowered flight with inlets closed. 


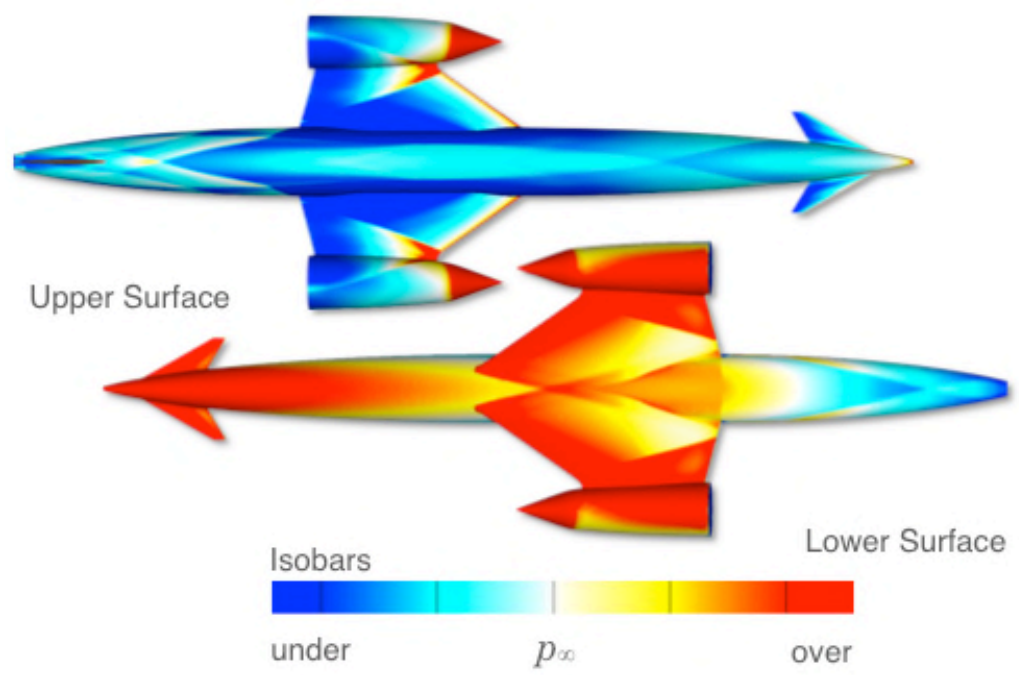

Figure 7. Isobars on the upper and lower surfaces at $\mathrm{M}_{\infty}=5.0$ and $\alpha=10^{\circ}$ for unpowered flight with inlets closed.

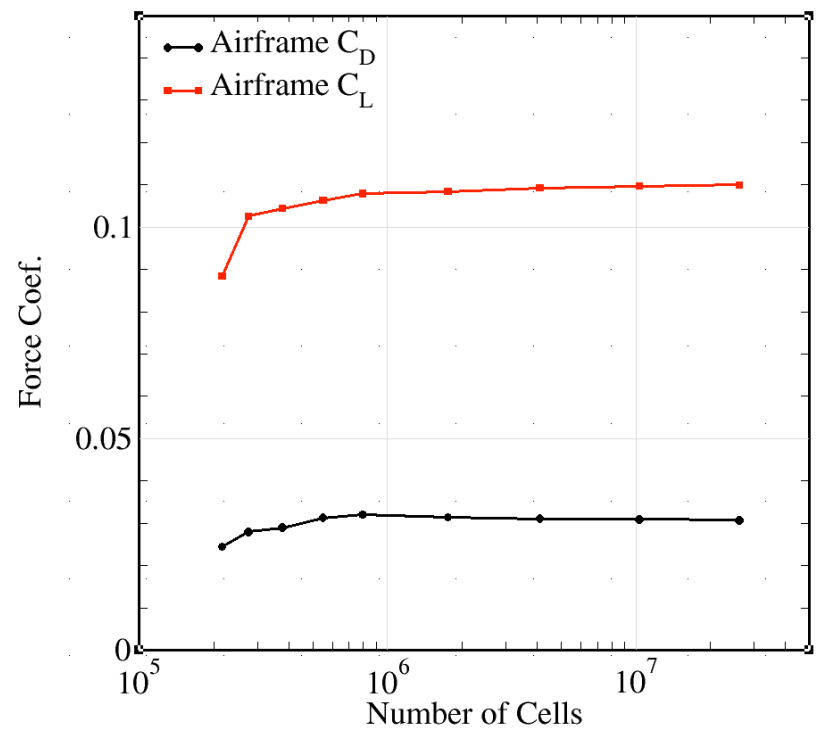

(a) Convergence of pressure forces

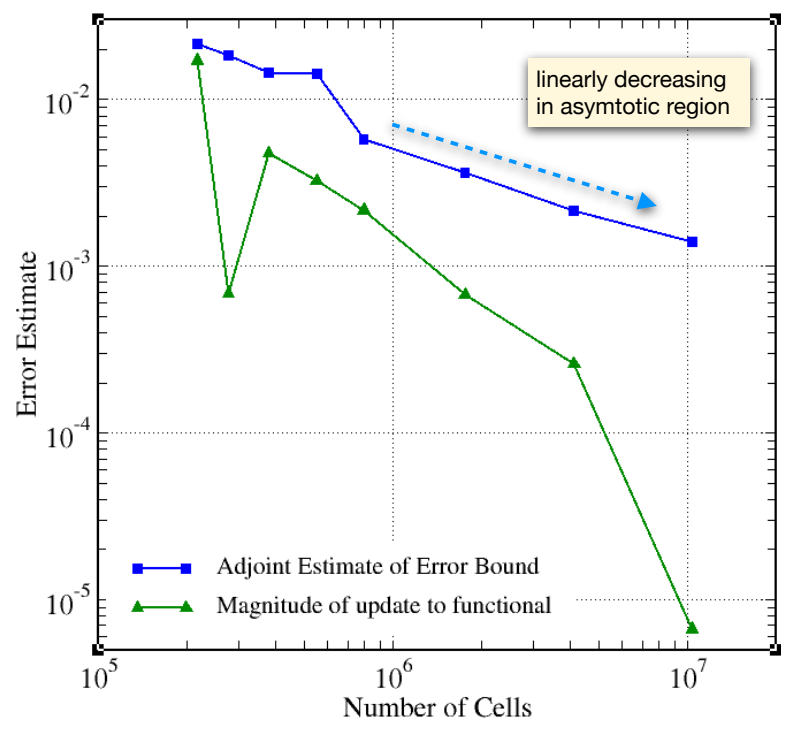

(b) Convergence of error estimates and update to functional

Figure 8. Mesh convergence for turbo-ramjet-powered flight at $\mathrm{M}_{\infty}=3.508, \alpha_{\mathrm{v}}=4.521^{\circ}$, and $\alpha_{\mathrm{f}}=-0.294^{\circ}$.

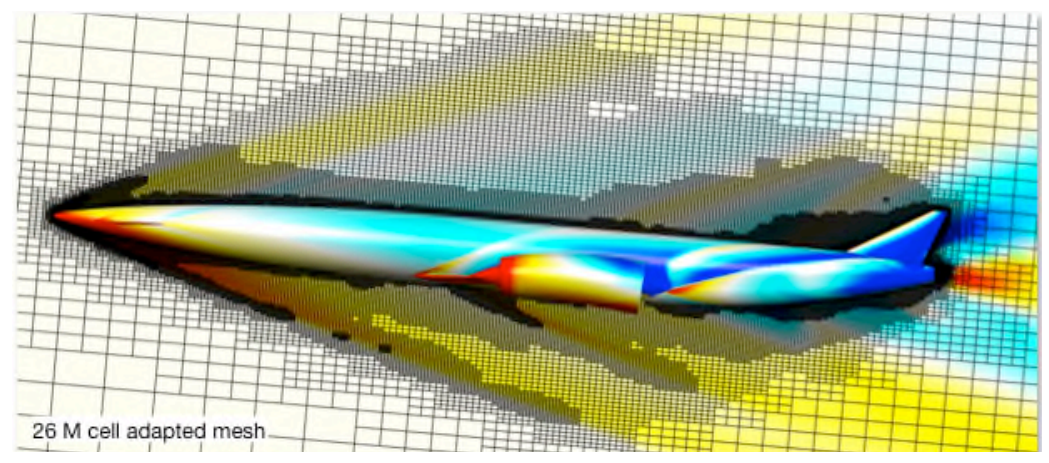

Figure 9. Cell distribution in the symmetry plane and flow field isobars for turbo-ramjet-powered flight at $\mathrm{M}_{\infty}=3.508, \alpha_{\mathrm{v}}=4.521^{\circ}$, and $\alpha_{\mathrm{f}}=-0.294^{\circ}$. 
The cell distributions for cases (i), (ii), and (iii) differ in figures 7, 9, and 11, respectively, because freestream conditions and engine operations are different. The simulation method used here automatically tailors the mesh to flow conditions such that the desired level of credibility in the force coefficient is achieved.

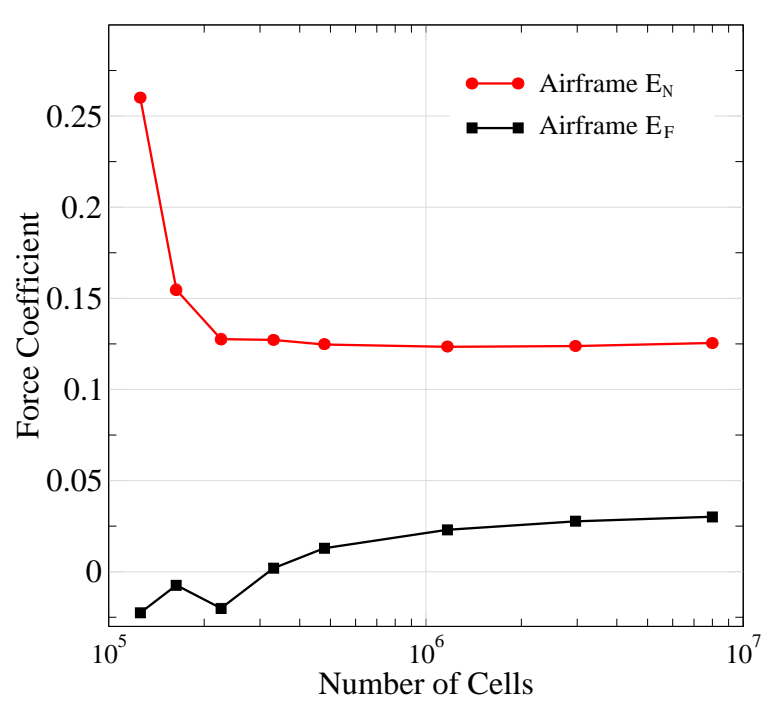

(a) Convergence of pressure forces

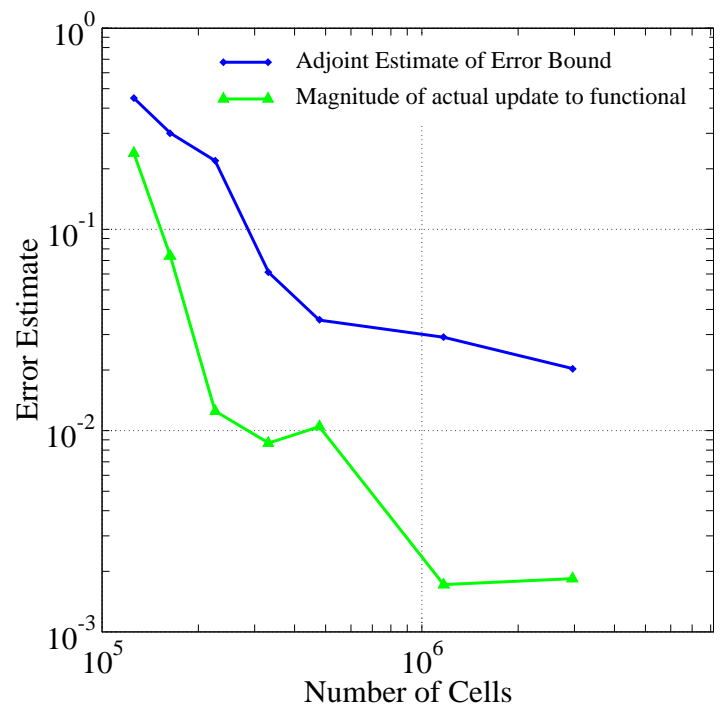

(b) Convergence of error estimates and update to functional

Figure 10. Mesh convergence for rocket-powered flight at $\mathrm{M}_{\infty}=12.189$ and $\alpha_{\mathrm{v}}=7.512^{\circ}$.

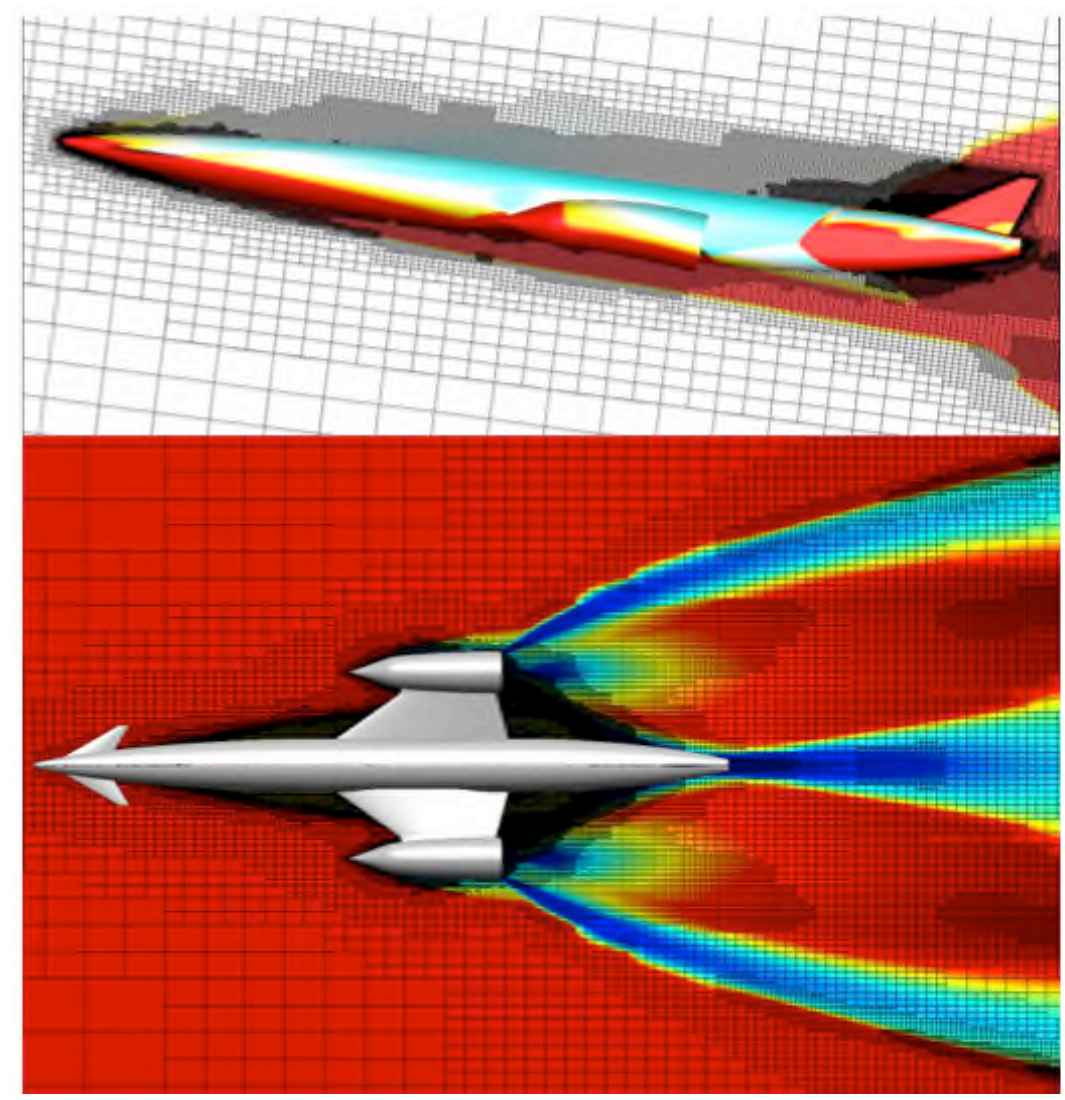

Figure 11. Cell distribution and flow field isobars in the symmetry plane (top) and top view (bottom) for rocketpowered flight at $\mathrm{M}_{\infty}=12.189$ and $\alpha_{\mathrm{v}}=7.512^{\circ}$. 


\section{Airframe Aerodynamics and Thermal Environment}

At select flight conditions, the aerodynamics of Skylon D1.5a is assessed when the engine is operated in turboramjet and rocket modes. Aerodynamic data produced by REL's engineering methods are checked against those derived from Cart3D simulations at flight conditions listed in Table 1.

The Mach fields in a horizontal plane as observed from the top of an unpowered Skylon are presented in Figs. 12(a) for Case 1 (Table 1) and 12(b) for Case 2, respectively, with the engine inlet closed and open, and with the inlet cone at $2690 \mathrm{~mm}$ upstream of the inlet entrance. The shock waves on the wings have a more complex structure and the flow field downstream of the nacelles is quite different when the inlets are closed than when they are open. The computed airframe pressure forces for Case 2 are compared with those determined with engineering methods by REL (Table 2). The agreement is excellent.

Table 1. Simulated Flight Conditions.

\begin{tabular}{|c|c|c|c|c|c|c|}
\hline Case & $\begin{array}{c}\text { Mach } \\
\text { Number, } \mathbf{M}_{\infty}\end{array}$ & $\begin{array}{c}\text { Altitude, } \\
\mathbf{k m}\end{array}$ & $\begin{array}{c}\text { Vehicle Alpha, } \\
\boldsymbol{\alpha}_{\mathbf{v}}, \mathbf{d e g} .\end{array}$ & $\begin{array}{c}\text { Foreplane } \\
\text { Alpha, } \boldsymbol{\alpha}_{\mathbf{f}}, \mathbf{d e g} .\end{array}$ & $\begin{array}{c}\text { Dynamic } \\
\text { Pressure, Pa }\end{array}$ & $\begin{array}{c}\text { Engine } \\
\text { Mode }\end{array}$ \\
\hline 1 & 2.625 & 15.326 & 3.673 & 0.928 & 55486 & Inlet close; none. \\
\hline 2 & 2.702 & 15.833 & 3.980 & 0.858 & 53985 & Inlet open; none. \\
\hline 3 & 3.508 & 18.537 & 4.521 & -0.294 & 59412 & Turbo-ramjet \\
\hline 4 & 5.188 & 28.084 & 6.577 & 6.577 & 30055 & Rocket or none \\
\hline 5 & 5.490 & 30.392 & 7.693 & 7.693 & 23815 & Rocket or none \\
\hline 6 & 5.936 & 33.852 & 9.324 & 9.324 & 16713 & Rocket or none \\
\hline 7 & 6.673 & 39.695 & 11.583 & 11.583 & 9322 & Rocket or none \\
\hline 8 & 7.483 & 45.722 & 12.779 & 12.779 & 5330 & Rocket or none \\
\hline 9 & 8.577 & 51.983 & 12.453 & 12.453 & 3210 & Rocket or none \\
\hline 10 & 10.131 & 58.483 & 10.626 & 10.626 & 1965 & Rocket or none \\
\hline 11 & 12.189 & 65.160 & 7.512 & 7.512 & 1163 & Rocket or none \\
\hline 12 & 14.952 & 71.854 & 3.510 & 3.510 & 648 & Rocket or none \\
\hline 13 & 16.969 & 75.771 & 0.907 & 0.907 & 440 & Rocket or none \\
\hline
\end{tabular}

Powered flight simulations are conducted for Cases 3-13 (Table 1). At $\mathrm{M}_{\infty}=3.508$, the SABRE 4/Ames engine is operated in turbo-ramjet mode (Case 3). The foreplane is at $\alpha_{\mathrm{f}}=-0.2942^{\circ}$ and the inlet cone is extended upstream of the inlet face by $2900.1 \mathrm{~mm}$. At other Mach numbers, the foreplane is at the same angle as the vehicle angle of attack, the inlet is closed, and powered (with SABRE operating in the rocket mode) and unpowered flight simulations are conducted.

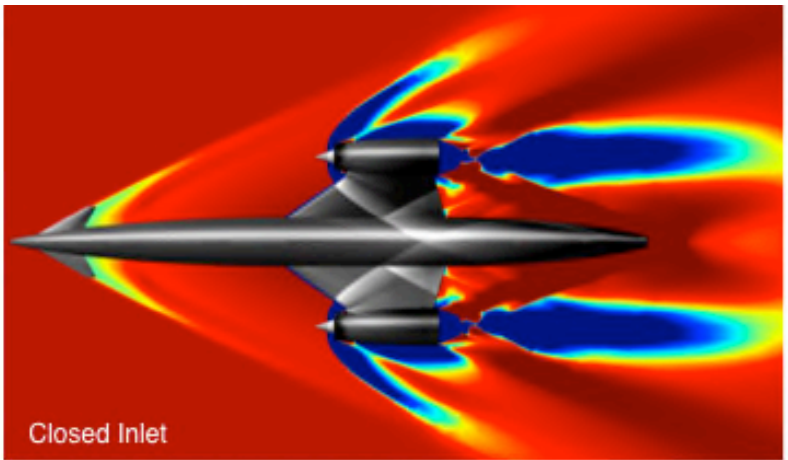

(a) $M_{\infty}=2.6247, a_{v}=3.673^{\circ}, \& a_{f}=0.928^{\circ}$

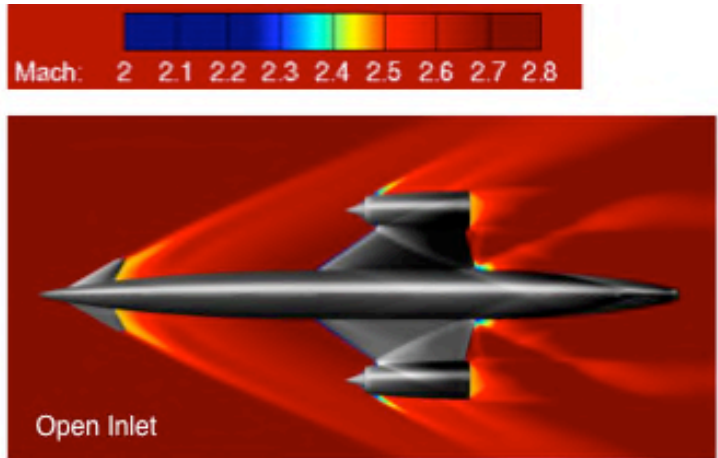

(b) $M_{\infty}=2.702, a_{v}=3.98^{\circ}, \& a_{f}=0.858^{\circ}$

Figure 12. Mach number contours and shock patterns for unpowered flight with (a) inlets close and (b) inlets open.

At $\mathrm{M}_{\infty}=3.508, \alpha_{\mathrm{v}}=4.521^{\circ}$, and $\alpha_{\mathrm{f}}=-0.294^{\circ}$ with the turbo-ramjet operational, Figure 13 presents nondimensional temperature patterns in nacelle plumes, Mach contours, and cell distributions in different planes. The width of the nacelle plume in the vicinity of Skylon is nearly the same as the width of the aft end of SABRE. The interaction of engine exhaust from four nozzles and from the bypass duct creates a complex flow field. Nacelle plumes do not impact or engulf the Skylon empennage. The inlet cone forms a shock wave that hits the fuselage in a 
region upstream of the empennage. Figure 14 compares pressure forces derived from Cart3D simulations and those obtained with engineering methods by REL, with $C_{L}$ comparing very well and $C_{D}$ not so well. Consequently, the lift/drag ratio is overestimated by the engineering methods.

Table 2. Airframe Pressure Forces with Flow Through Unpowered Engine at $M_{\infty}=2.702, \alpha_{\mathrm{f}}=0.858^{\circ}$, and $\alpha_{\mathrm{v}}=3.98^{\circ}$.

\begin{tabular}{|c|c|c|}
\hline Airframe Force & Cart3D & REL \\
\hline Lift, $C_{\mathrm{L}}$ & 0.129 & 0.127 \\
\hline Drag, $_{\mathrm{D}}$ & 0.0287 & 0.0291 \\
\hline $\mathrm{C}_{\mathrm{L}} / \mathrm{C}_{\mathrm{D}}$ & 4.495 & 4.364 \\
\hline
\end{tabular}
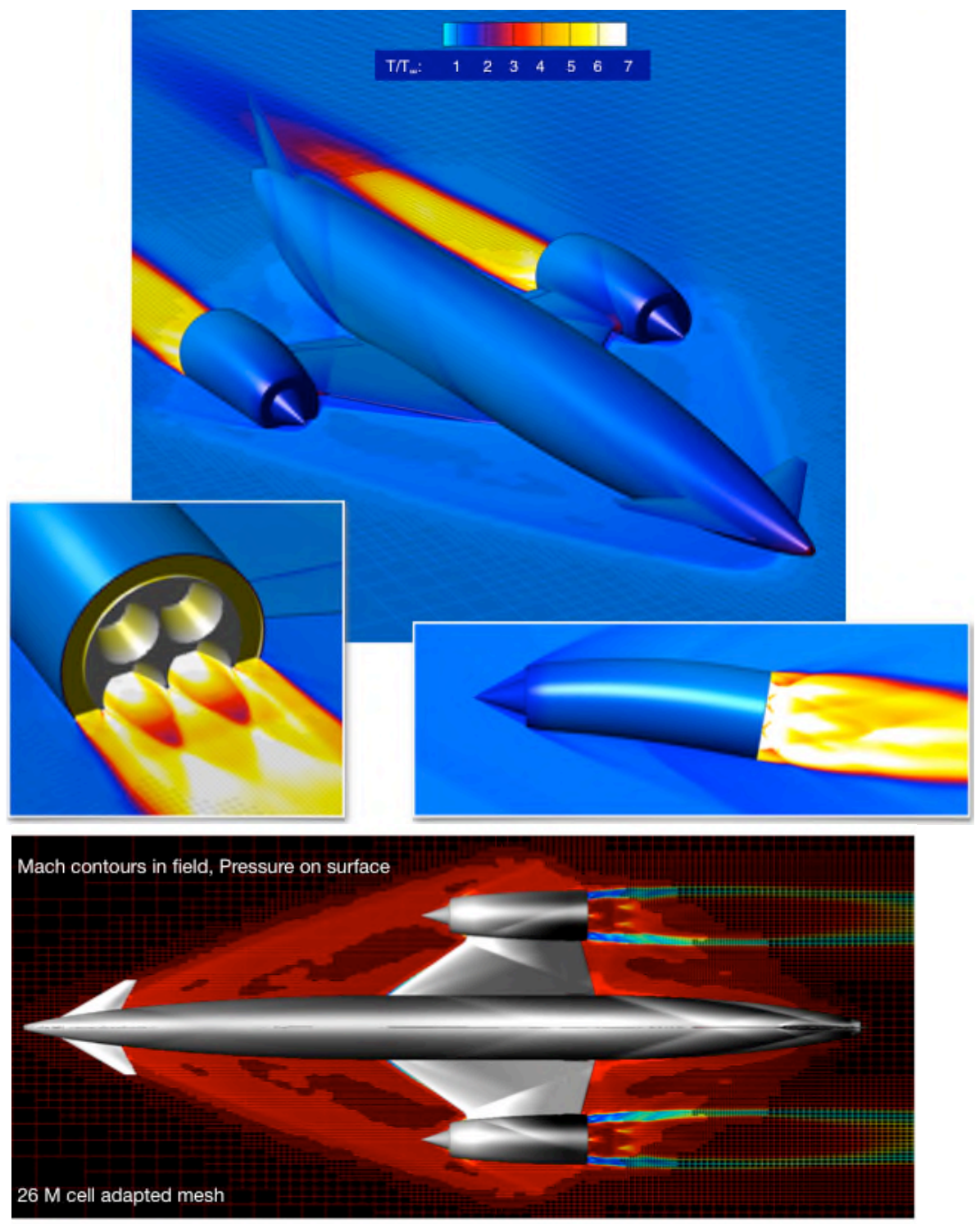

Figure 13. Plume static temperature, Mach contours in field, pressure on surface, and mesh for turbo-ramjet-powered flight at $\mathrm{M}_{\infty}=3.508, \alpha_{\mathrm{v}}=4.521^{\circ}, \alpha_{\mathrm{f}}=-0.294^{\circ}$, and $\mathrm{h}=18.537 \mathrm{~km}$.

Kaleidoscopic flow patterns are observed as the freestream Mach number is increased from 6.673 to 16.969 during the rocket-powered ascent flight. Figure 15 presents thermal environments around Skylon as viewed from the top. The SABRE/Skylon wake width increases as rocket plumes are increasingly under-expanded. Static temperatures in the fluid next to the wing increase as the freestream Mach number and altitude increase and the 
dynamic pressure decreases. The plume-freestream interaction regions are hotter than the core region of the plume downstream of Skylon at higher Mach numbers.

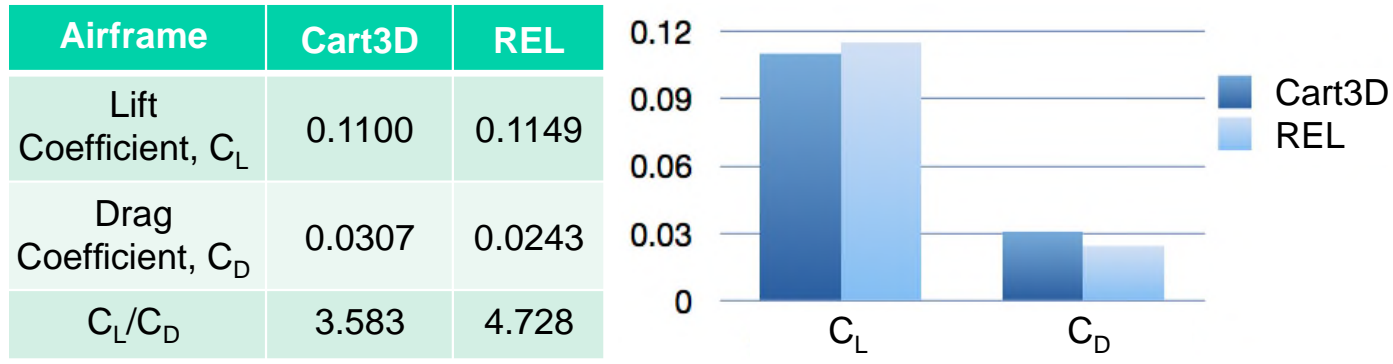

Figure 14. A comparison of the Cart3D and REL pressure forces at $\mathrm{M}_{\infty}=3.508, \alpha_{\mathrm{v}}=4.521^{\circ}$, and $\alpha_{\mathrm{f}}=-0.294^{\circ}$.

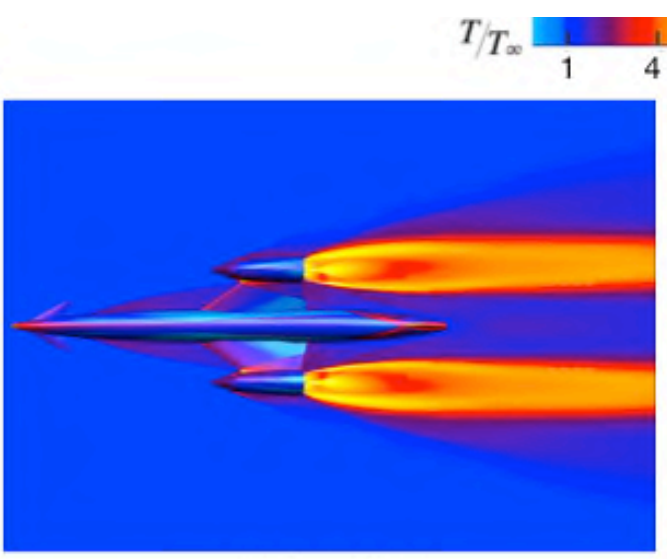

(a) $\mathrm{M}_{\mathrm{m}}=6.673$

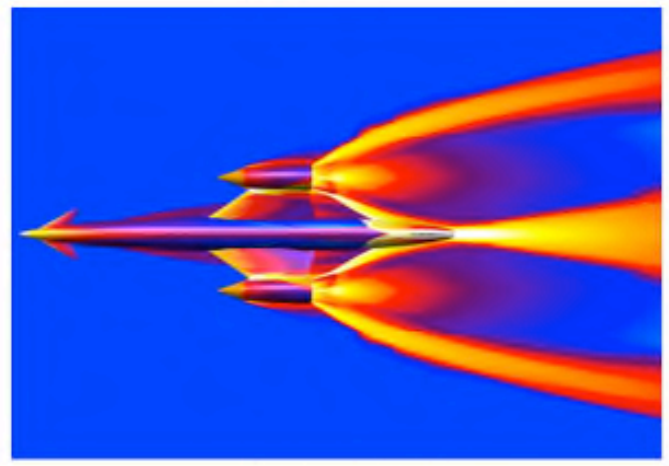

(c) $\mathrm{M}_{\infty}=12.189$

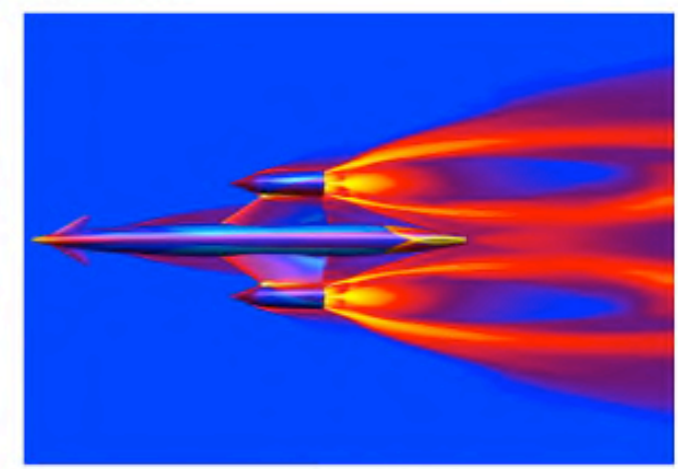

(b) $\mathrm{M}_{\mathrm{m}}=8.577$

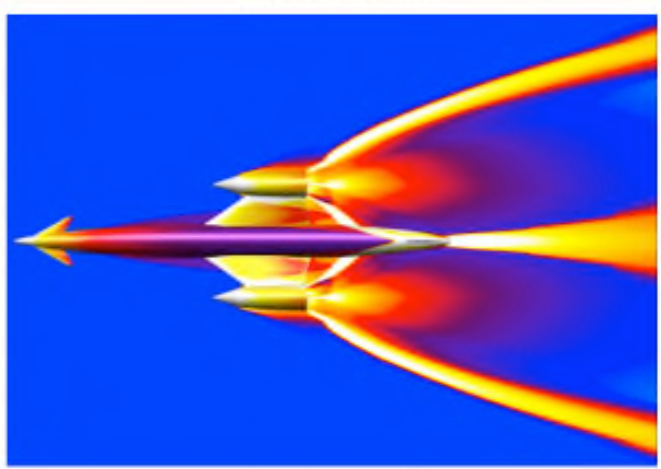

(d) $\mathrm{M}_{\mathrm{ot}}=16.969$

Figure 15. Thermal environments, as viewed from the top, during the SABRE operation in rocket mode.

A remarkable change in nacelle plume geometry via iso-stagnation enthalpy is observed in Figure 16, when the freestream Mach number is increased from $\mathrm{M}_{\infty}=6.673$ to 12.189 . At $\mathrm{M}_{\infty}=12.189$ and the altitude of $65.16 \mathrm{~km}$, the nacelle plumes engulf the Skylon aft fuselage. The normalized temperatures at $\mathrm{M}_{\infty}=12.189$ are significantly higher than those observed at $\mathrm{M}_{\infty}=3.508$ [Figs. 16(b) and 13].

Figure 17 presents perspective views of the thermal environment around the aft fuselage and in a plane downstream of a Skylon nacelle. At $\mathrm{M}_{\infty} \geq 12.189$, there are regions where the static temperature is roughly 8-16 times that of the freestream temperature. Where the SABRE plume shock wave hits the fuselage there is a static temperature spike. Subsequently, the static temperature again increases, as hot gases from engines pass over the aft fuselage [Figs. 17(c)-17 (d)]. As seen in Fig. 18, two plume shock waves, one from each SABRE, intersect at the vehicle symmetry plane. In front of the vertical tail, there is a bow shock wave. This shock wave also elevates static temperatures on the fuselage around the base of the vertical tail. 


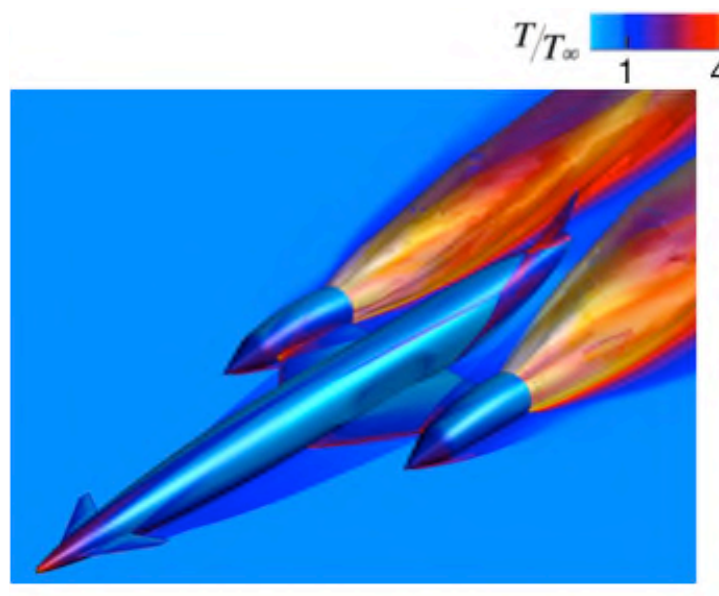

(a) $M_{\infty}=6.67$, Alt. $=39.69 \mathrm{~km}, \mathrm{a}=11.58^{\circ}$, $\mathrm{T}_{\infty}=250.2^{\circ} \mathrm{K}, \mathrm{p}_{\infty}=289.3 \mathrm{~Pa}$.
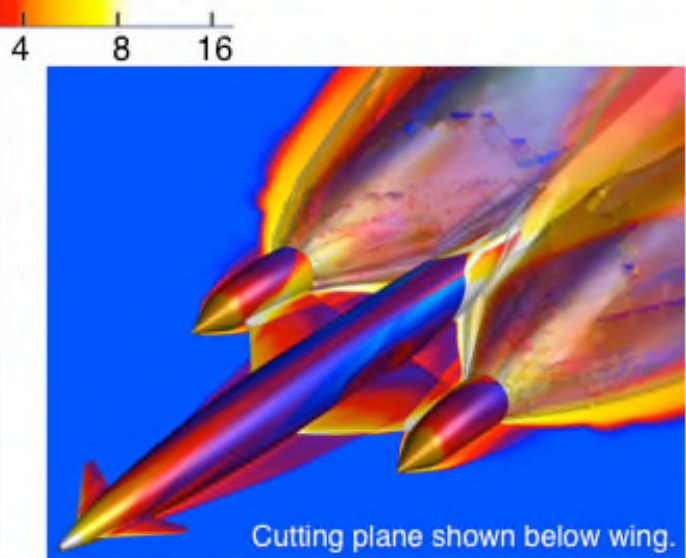

(b) $\mathrm{M}_{\mathrm{m}}=12.19$, Alt. $=65.16 \mathrm{~km}, \mathrm{a}=7.51^{\circ}$, $\mathrm{T}_{\infty}=231.0^{\circ} \mathrm{K}, \mathrm{p}_{\infty}=9.69 \mathrm{~Pa}$.

Figure 16. Thermal environments around Skylon and nacelle plume geometries via iso-stagnation enthalpy for rocket-powered flights at indicated freestream Mach numbers.

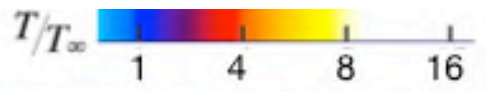

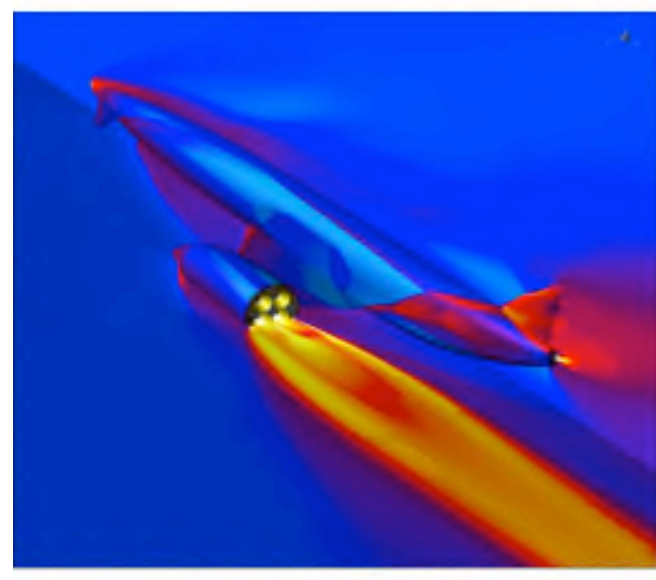

(a) $\mathrm{M}_{\infty}=6.673$

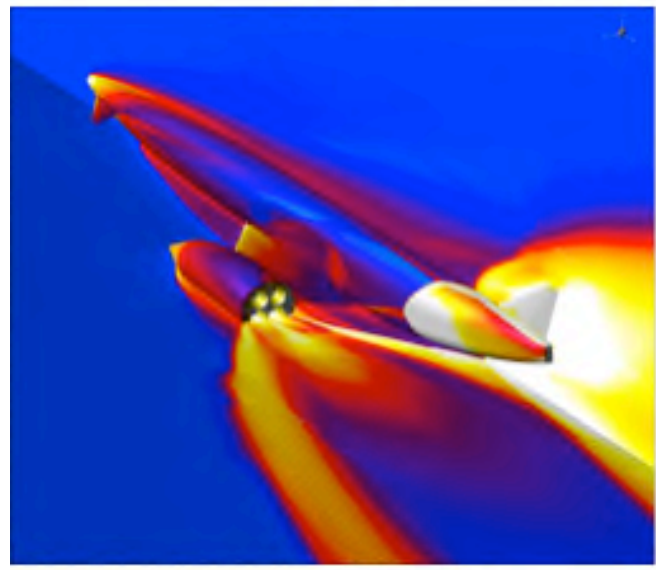

(c) $\mathrm{M}_{\infty}=12.189$

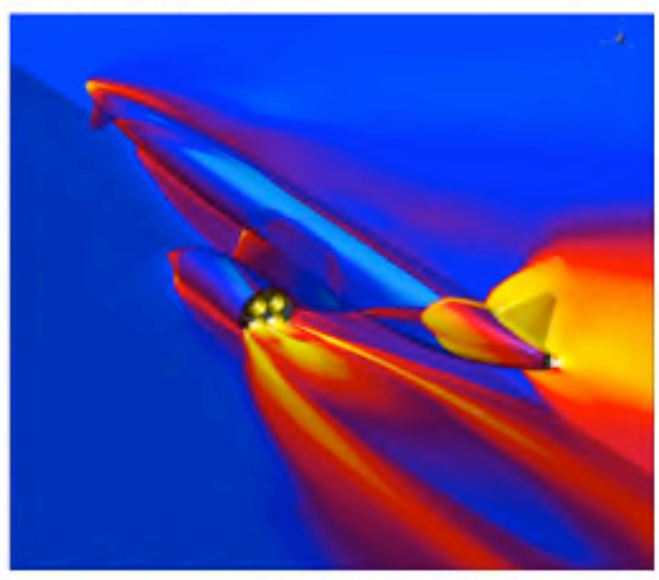

(b) $\mathrm{M}_{\infty}=8.577$

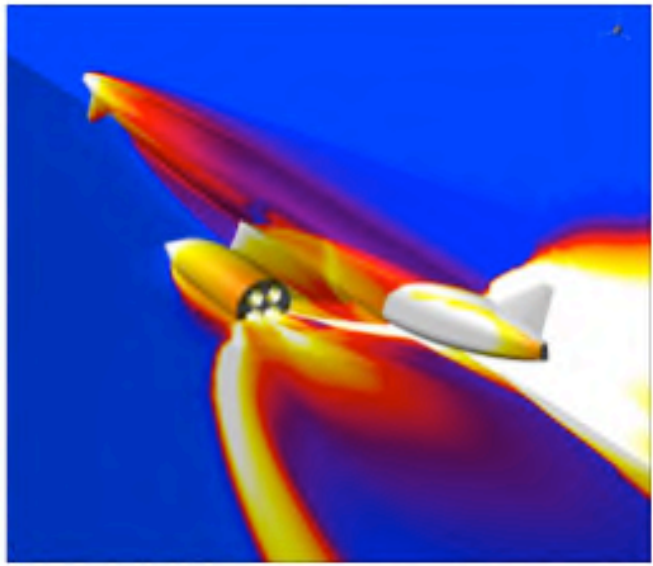

(d) $M_{\infty}=16.969$

Figure 17. Thermal environments around the aft fuselage and in a plane through the center of lower two SABRE nozzles, during the SABRE operation in rocket mode at indicated freestream Mach numbers. 


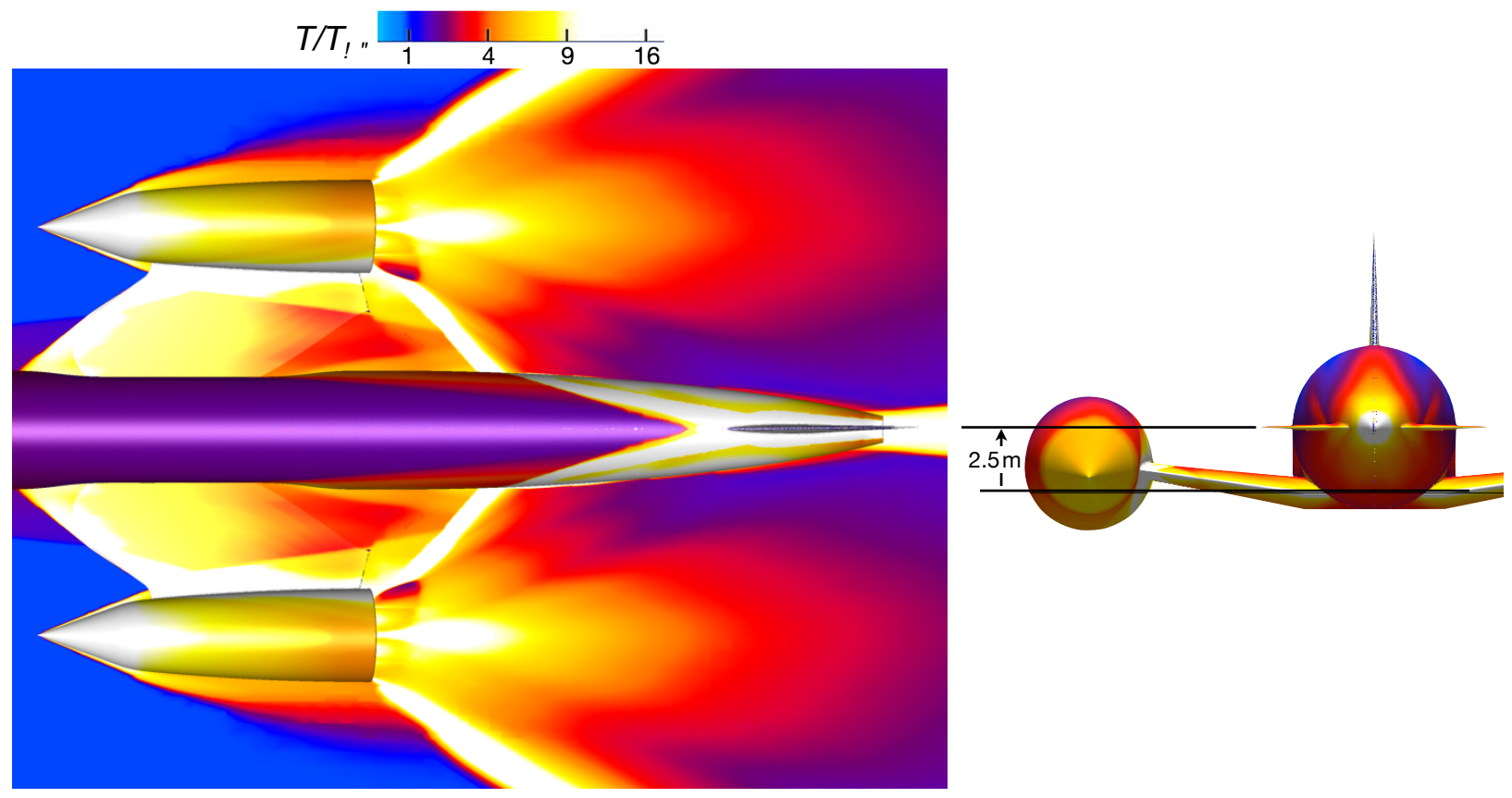

Figure 18. An enlarged top view of the thermal environment around the aft fuselage and in a cutting plane at $\mathrm{y}=-2.5 \mathrm{~m}$ of Skylon at $\mathrm{M}_{\infty}=16.969$.

At $\mathrm{M}_{\infty}=16.969$, approximately 20 percent of the aft portion of the fuselage, including the empennage, is surrounded by fluid at very high static temperatures. As the rocket mode is used to raise $M_{\infty}$ beyond 17 , the percentage of fuselage engulfed with nacelle plumes will further increase and the thermal environment will become increasingly severe. The thermal environment will also depend on how the SABRE nozzles are gimbaled. However, the plumes are so under-expanded that it is unlikely this will substantially alleviate the impingement effects.

At $M_{\infty}=12.189$ for a perfect gas $(\gamma=1.4)$, the freestream total temperature is approximately 30 times $_{\infty}=231^{\circ}$ $\mathrm{K}$, and the freestream recovery temperature is roughly 26 times $\mathrm{T}_{\infty}$. However, based on real gas chemistry and the edge pressure $=$ atmospheric pressure, the freestream total and recovery temperatures are, respectively, nearly 13 and 11 times the freestream temperature (as shown in Table 3). Here, the assumed recovery factor is 0.85 .

Table 3. The freestream total and recovery temperatures for a real gas.

\begin{tabular}{|c|c|c|c|c|c|c|c|}
\hline $\mathbf{M}_{\infty}$ & Altitude, ft & $\mathbf{p}_{\infty}, \mathbf{p s i}$ & $\mathbf{T}_{\infty},{ }^{\circ} \mathbf{R}$ & $\mathbf{T}_{\text {tot }},{ }^{\circ} \mathbf{R}$ & $\mathbf{T}_{\text {tot }} / \mathbf{T}_{\infty}$ & $\mathbf{T}_{\text {rec }},{ }^{\circ} \mathbf{R}$ & $\mathbf{T}_{\text {rec }} / \mathbf{T}_{\infty}$ \\
\hline 10.13 & 190285 & 0.004166 & 445.0 & 4588.0 & 10.31 & 4400.0 & 9.89 \\
\hline 12.19 & 213252 & 0.001583 & 419.9 & 5367.0 & 12.78 & 4632.6 & 11.03 \\
\hline 14.95 & 235561 & 0.000573 & 387.4 & 6735.8 & 17.39 & 6282.6 & 16.22 \\
\hline 16.97 & 248685 & 0.000304 & 372.0 & 6971.2 & 18.74 & 6717.0 & 18.06 \\
\hline
\end{tabular}

Because Cart3D simulated temperatures are based on Euler equations for a perfect gas, they do not translate directly into fuselage skin temperatures. The surface equilibrium radiation thermal environment will differ when simulations are conducted with air and hydrogen/oxygen chemistry and account for viscous, plume radiation, and real gas $(\gamma \sim 1.3)$ effects. This level of physics will provide information such as surface temperatures, flow separation, and realistic effects of shock-shock/boundary interactions and vertical tail bow shock/boundary layer interactions. Nevertheless, the fundamental fluid phenomena will remain the same.

High-temperature gas has the ability to emit significant radiation in the UV, visible, and IR regions of the electromagnetic spectrum, leading to potentially substantial heating of the aft fuselage surface. Radiative processes augment the convective heating. At the expected temperatures, an estimated radiative heating of the body surfaces can be reasonably obtained using a gray-gas model. Should the estimated radiative heating turn out to be a significant fraction of the convective heating, a compositional distribution, in terms of gas species populations, 
would be necessary for conducting a full-line radiation analysis in order to perform an accurate radiation assessment. $^{58}$

Two of the key problems with the HOTOL design were the far aft location of the center of gravity and the poor control authority with far aft wings. The solutions to these problems determined the locations of the SABRE engines and wings on the Skylon concept. If the aft fuselage heating at $\mathrm{M}_{\infty}>8.5$ is an issue that cannot be addressed with appropriate structures and materials, then the overall design of Skylon D1.5a needs to be changed while minimizing (or without re-introducing) these HOTOL problems.

Figure 19 presents the pressure field around Skylon as viewed from the top, at different Mach numbers. As the Mach number and spaceplane altitude are increased and the dynamic pressure is decreased, relative pressure near the aft end of the Skylon fuselage increases, which in turn favorably affects the airframe force coefficients by both increasing $C_{L}$ and reducing $C_{D}$.

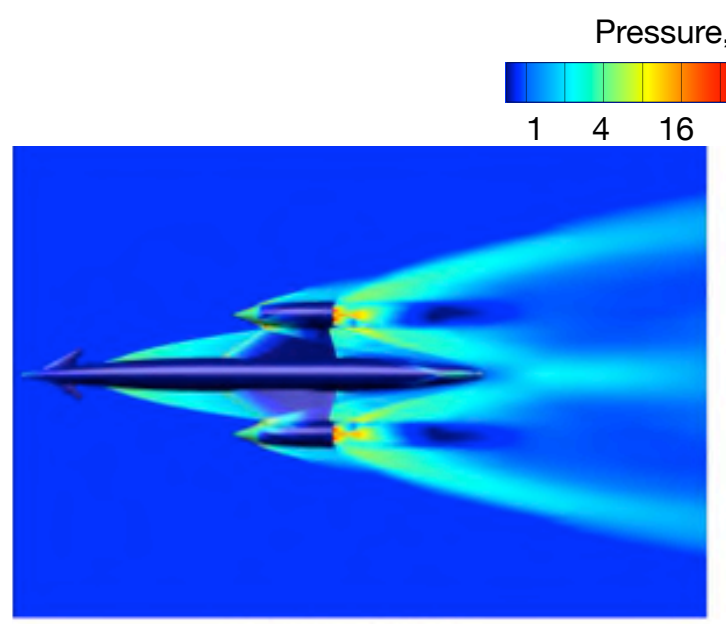

(a) $M_{m}=6.673$

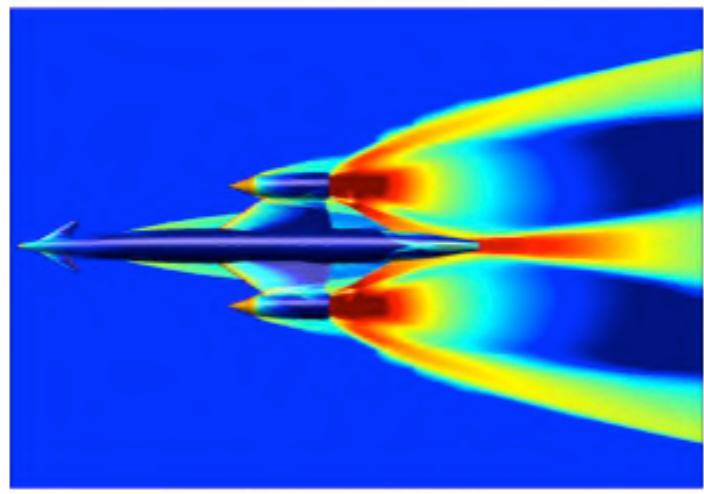

(c) $\mathrm{M}_{\infty}=12.189$

Figure 19. Pressure fields as viewed from the top

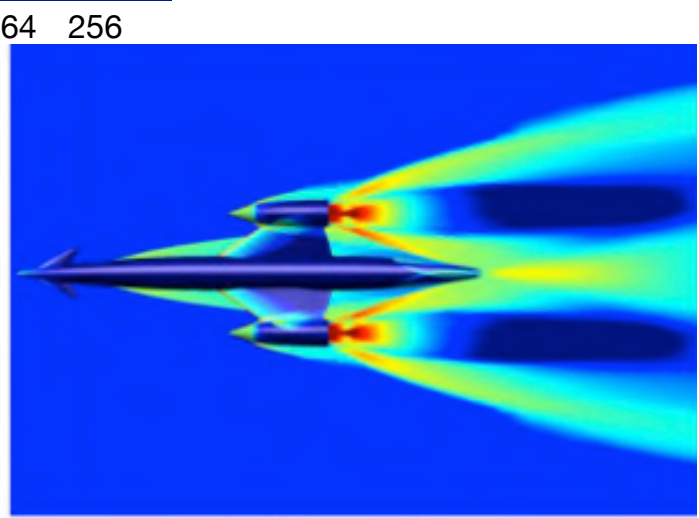

(b) $\mathrm{M}_{\infty}=8.577$

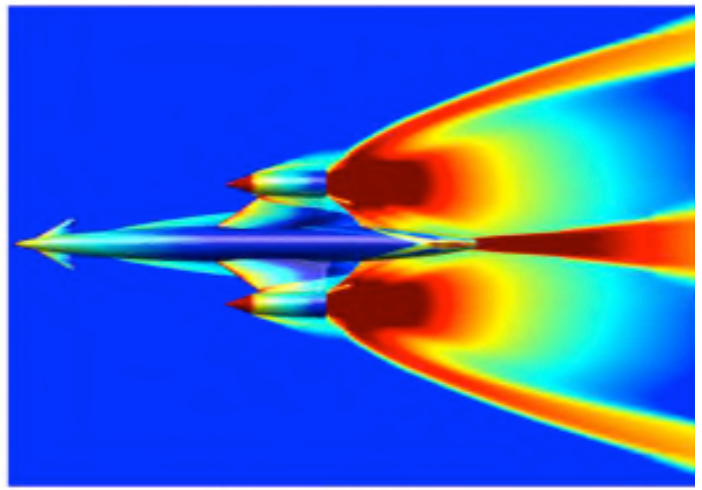

(d) $M_{\infty}=16.969$

for rocket-powered flights at indicated freestream Mach numbers.

Figure 20 compares pressure lift and drag coefficients as determined by Cart3D simulations (with and without rocket power) and those determined with engineering methods by REL. The Cart3D lift coefficients for the poweroff conditions compare extremely well with those REL provided. The comparison of drag coefficients is less satisfactory, but still in generally good agreement. The key differences in airframe $C_{L}\left(=C_{L_{\text {ppowered }}}-\mathrm{C}_{\mathrm{L}_{-} \text {thrust }}\right)$ and $\mathrm{C}_{\mathrm{D}}$ $\left(=\mathrm{C}_{\mathrm{D} \text { _powered }}-\mathrm{C}_{\mathrm{D}_{-} \text {thrust }}\right)$, as derived from Cart3D simulations and REL data (lift and drag coefficients) are for powered flight at $\bar{M}_{\infty}>8.5$ when nacelle plumes begin to engulf the aft fuselage. The impact of plumes on airframe aerodynamics is not accounted for in REL's method of computing forces. The detrimental effect of this shortcoming increases with $\mathrm{M}_{\infty}$ increasing beyond 8.5, as illustrated by the yellow region indicating the plume interaction with the aft fuselage in Fig. 20. 

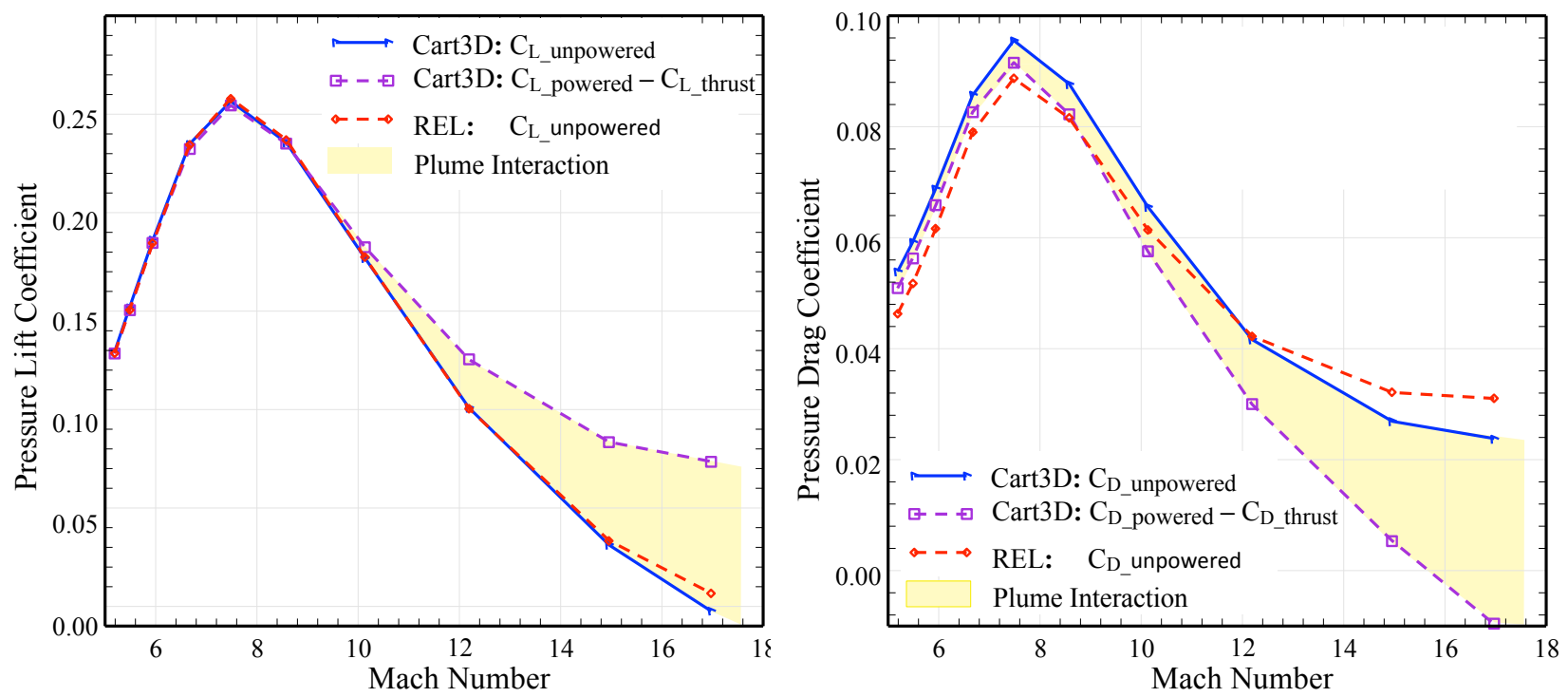

Figure 20. Effects of jet interactions on pressure forces.

Another potential adverse impact of nacelle plumes is the effect of plume-induced flow separation (PIFS) on nacelles. On Apollo 11, PIFS distances were $15 \mathrm{~m}$ and $33 \mathrm{~m}$, respectively at $\mathrm{M}_{\infty}=4.4$ and $\mathrm{p}_{\infty}=151 \mathrm{~Pa}$, and at $\mathrm{M}_{\infty}=$ 6.5 and $\mathrm{p}_{\infty}=22 \mathrm{~Pa}$ (Fig. 21). The PIFS effect can only be determined with viscous simulations. This effect will increase the portion of airframe (aft fuselage, wings, and nacelle) is engulfed by SABRE plumes. The thermal environment of the engulfed portions of Skylon may have an adverse effect on structures and materials. The PIFS effect may affect the airframe aerodynamics. Additionally, shock waves interacting with boundary layers may cause flow separation. If plumes and shock waves adversely affect performance, mission, cost goals, or reusability, some adjustments in design, mission, flight profile, or propulsive power may be required.
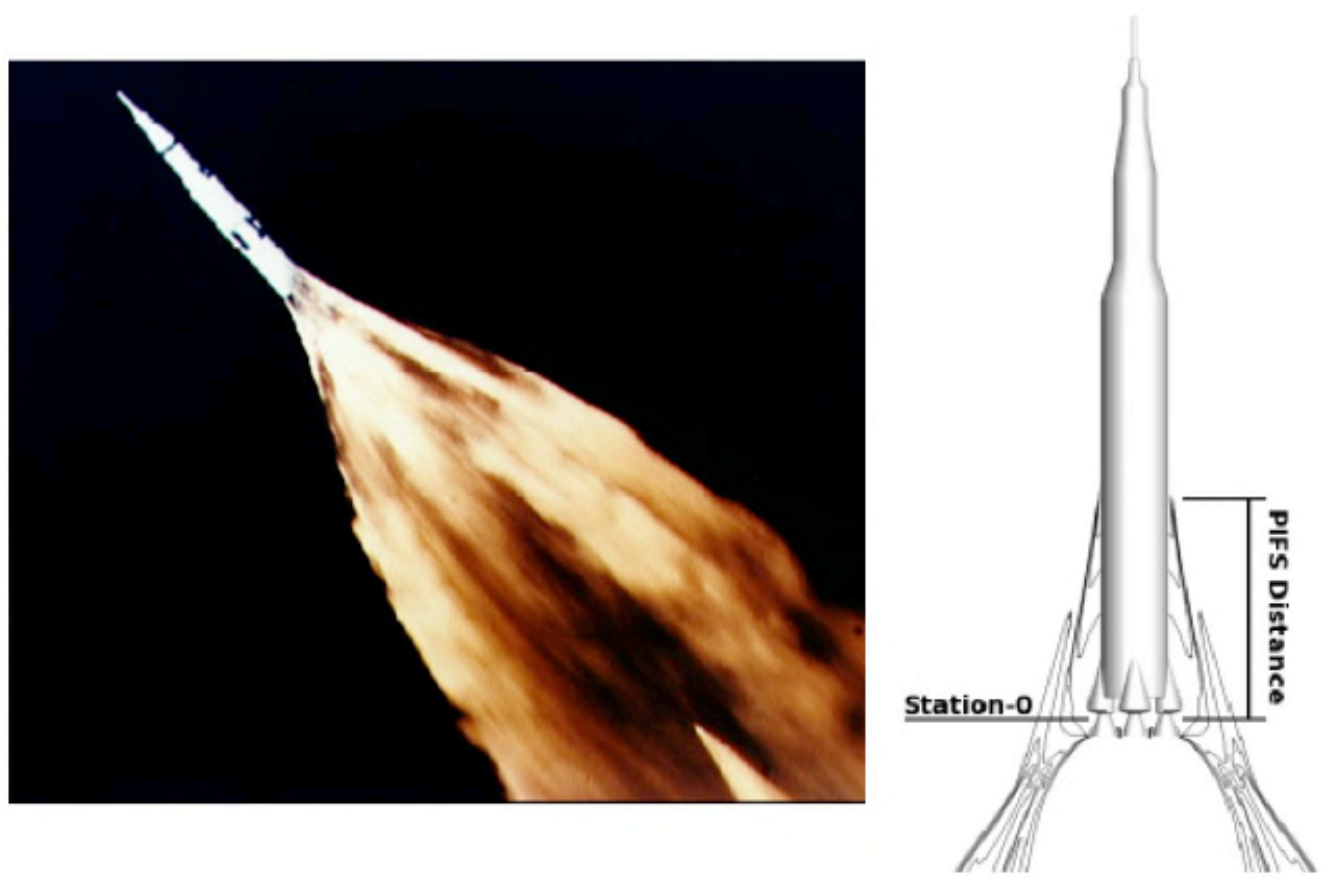

Figure 21. Plume-induced flow separation (PIFS) on Apollo $11 .^{59}$ 


\section{Takeaway}

A revolutionary propulsion breakthrough is potentially feasible with the REL heat exchanger technology. It may provide a paradigm change in the transportation of medium-weight payloads to LEO with respect to affordability, reliability, safety, resiliency, and operational responsiveness. It may also make hypersonic transport a reality. This technology is used in a conceptual design of the SABRE engine. The conceptual Skylon aerospace plane is powered with this innovative and game-changing air-breathing-rocket combined cycle (ARCC) engine. Here, we studied both the Skylon airframe aerodynamics during powered flight and the impact of engine plumes on the aft fuselage, in order to provide a value-added independent assessment.

At all flight conditions considered, CFD simulations were conducted with the Cart3D package. Fluid is considered to be inviscid perfect gas with no radiation. Although air is used as the simulant fluid, care is taken to match both exit pressure and total thrust to those accounting for combustion chemistry effects in the SABRE nozzles. The credibility of the simulations is established with computational mesh refinement. The final forces derived from the simulations are independent of the computational mesh.

The adverse thermal impact of an under-expanded plume on the aft fuselage increases as $\mathrm{M}_{\infty}$ increases above $\mathrm{M}_{\infty}=8.5$. The simulation at $\mathrm{M}_{\infty} \geq 12.19$ shows that downstream of the SABRE engines there are regions where static temperatures are roughly 8-16 times greater than the freestream temperature. From $\mathrm{M}_{\infty}=10.13$ to 16.97 , the freestream total and recovery temperatures (normalized with freestream temperatures), based on real gas chemistry and atmospheric pressure and with a value of 0.85 for the recovery factor, vary from 10.31 to 18.74 and from 9.89 to 18.06 , respectively.

As simulated thermal environments are based on Euler equations with $\gamma=1.4$, they do not provide quantitatively the fuselage skin temperatures. Viscous simulations, including (i) air and hydrogen/oxygen chemistry, (ii) radiant heating from plumes, (iii) proper heat transfer condition at the Skylon surface, and (iv) proper $\gamma$, are necessary to determine surface temperatures. Viscous simulations are also needed to determine PIFS on the nacelles and the aft fuselage.

If the aft fuselage heating owing to nacelle plumes is an issue that cannot be addressed with appropriate structures and materials, then the overall design of Skylon needs to be modified. Detrimental effects of PIFS, shock waves related boundary layer separations and shock-shock interactions might also require some adjustments in design, mission, flight profile, or propulsive power.

Unpowered airframe pressure lift and drag coefficients, determined with Cart3D, generally agree with those that REL computed with engineering methods. The comparisons of lift and drag coefficients are excellent and good, respectively. During powered flight, the nacelle plume significantly increases fluid over-pressure at $\mathrm{M}_{\infty}>8.5$ in the immediate vicinity of the Skylon aft fuselage. This favorable impact of plumes and the complex shock structures pressurize the aft fuselage. Consequently, the airframe lift coefficient increases and airframe drag coefficient decreases. The force coefficients based on engineering methods do not account for the impact of plumes and plume shocks on the aft fuselage.

The highly innovative Skylon concept has the potential to evolve into an operational reusable launcher for a viable transport to LEO. The ultimate goal would be a SABRE-propelled SSTO RLV. However, the fallback or near-term objective should be a TSTO system. This system would comprise a SABRE-powered reusable launcher (first stage) and an expendable or reusable second stage that would be staged at approximately at $7.16 \mathrm{~km} / \mathrm{s}$. This staging velocity could allow the first stage to go around the world and return to the launch site ${ }^{60}$ and could lead to the second stage to be small enough to be carried in the payload bay of the first stage.

The development of the operational reusable launcher from the Skylon concept necessitates the judicious use of a combination of engineering methods, advanced methods based on required physics or analytical fidelity, test data, and independent assessments, with the focus on the figures of merit mentioned in Section I for securing viability. That development requires visionary leadership and will.

\section{Acknowledgement}

Reaction Engine Limited provided Skylon concept data. Jill Dunbar, Computer Sciences Corporation, provided editorial consultation. 


\section{References}

${ }^{1}$ Augenstein, B. W., Harris, E. D., with Aroesty, J., Blumenthal, L., Brooks, N., Frelinger, D., Garber, T., Gottenmoeller, R., Hiland, J., Liu, S. K., Pace, S., Rosen, J., Rowell, L., and Stucker, J., "The National Aerospace Plane (NASP): Development Issues for the Follow-on Vehicle, Executive Summary,” RAND, R3878/1-AF, Santa Monica, CA, 1993.

${ }^{2}$ Butrica, A. J., "Reusable Launch Vehicles or Expendable Launch Vehicles? A Perennial Debate," Critical Issues in the History of Spaceflight, Eds. S. Dick and R. Launius, NASA SP-4702, 2006.

${ }^{3}$ Hallion, R. P. and Young, J. O., "Space Shuttle: Fulfillment of a Dream," The Hypersonic Revolution, Vol. 2, ed. R. P. Hallion, Aeronautical Systems Div., Wright-Patterson AFB, OH, 1987, p. 1036.

${ }^{4}$ Jenkins, D., Space Shuttle, The History of the National Transportation System, ${ }^{\text {rd }}$ Ed., 2001, p. 108, ISBN: 09633974-5-1.

${ }^{5}$ Heppenheimer, T. A., The Space Shuttle Decision, NASA SP-4221, 1999.

${ }^{6}$ United States Air Force Scientific Advisory Board, "Report on Why and Whither Hypersonics Research in the US Air Force," SAB-TR-00-03, Dec. 2000, p. 6.

${ }^{7}$ Hannigan, R. J., Spaceflight in the Era of Aero-Space Planes, Krieger Publishing Co., 1994, p. 78.

${ }^{8}$ United States General Accounting Office, "National Aero-Space Plane, Restructuring Future Research and Development Efforts," GAO/NSTAD-93-71, Dec. 1992.

${ }^{9}$ Defense Science Board, OUSD, "Report of the Defense Science Board on National Aero-Space Plane (NASP) Program," Nov. 1992, p. 12.

${ }^{10}$ NASA, “Access to Space Study”, NASA-TM-109693, Jan. 1994.

${ }^{11}$ Mehta, U. and Bowles, J., "Two-Stage-to-Orbit Spaceplane Concept with Growth Potential," Journal of Propulsion and Power, Vol. 17, No. 6, Nov.-Dec. 2001, pp. 1149-1161

${ }^{12}$ Hunt J., Petley, D., Moses, P., Martin, J., Ferlemann, S., Leonard, C., Pegg, R., Robinson, J., Taylor III, L., Vause, R., Pinckney, S., and Bouchard, K., "Airbreathing Launch Vehicle Study," 50th JANNAF Propulsion Meeting, Salt Lake City, Utah, 11-13 July 2001.

${ }^{13}$ Hueter, U. and McClinton, C., "NASA's Advanced Space transportation Hypersonic Program," AIAA 20025175 .

${ }^{14}$ Hueter, U., "NASA's Next Generation Launch Technology Program - Strategy and Plans," IAC-03-V.5.01.

${ }^{15}$ USAF Scientific Advisory Board, "Report on Why and Whither Hypersonic Research in the US Air Force," SAB-TR-00-03, Dec. 2003, pp. 77-92.

${ }^{16}$ Bilardo, V., Hunt, J., Lovell, N., Maggio, G., Wilhite, A., and McKinney, L., "The Benefits of Hypersonic Airbreathing Launch Systems for Access to Space," AIAA 2003-5265.

${ }^{17}$ Culbertson, A. and Bhat, B., "The National Aerospace Initiative (NAI): Technologies for Responsive Space Access," http://ntrs.nasa.gov/archive/nasa/casi.ntrs.nasa.gov/20030107848.pdf.

${ }^{18}$ McClinton, C., Rausch, V., Shaw, R., Mehta, U., and Naftel, C., "Hyper-X: Foundation for future hypersonic launch vehicle," Acta Astronautics, Vol. 57, 2005, pp. 614-622.

${ }^{19}$ The Boeing Company, "Small Launch Vehicle," Patent US 20130299626 A1, Nov. 14, 2013.

${ }^{20}$ Mehta, U., Bowles, J., Pandya, S., Melton, J., Huynh, L., Kless, J., and Hawke, V., "Conceptual Stage Separation From Widebody Subsonic Carrier Aircraft For Space Access," The Aeronautical Journal, Vol. 118 , No. 1209, Nov. 2014, pp. 1279-1309.

${ }^{21}$ Allen, P.G. Announces revolution in space transportation, Stratolaunch Press Release, Stratolaunch Systems, 13 December 2011, http://www.stratolaunch.com.

${ }^{22}$ Virgin Galactic, "Satellite Launch," http://www.virgingalactic.com/satellite-launch/.

${ }^{23}$ Hannigan, R. J., "Sänger: A Lead Concept," Spaceflight in the Era of Aero-Space Planes, Krieger Publishing Co., 1994.

${ }^{24}$ United States General Accounting Office, “Aerospace Plane Technology, Research and Development Efforts in Europe," GAO/NSIAD-91-194, July 1991.

${ }^{25}$ Heitmer, F., Lederer, R., Voss, N., Bissinger, N., and Hermann, O., "Turboramjets and Installation," Developments in High-Speed-Vehicle Propulsion Systems, Eds. S. N. B. Murthy and E. T. Curran, Progress in Astronautics and Aeronautics, Vol. 165, 1996.

${ }^{26}$ Encyclopedia Astronautica (http://www.astronautix.com/):'Saenger II'.

${ }^{27} \mathrm{Li}, \mathrm{A}$., "Critical Areas NASA Needs to Address in Managing Its Reusable Launch Vehicle Program," GAO01-826T, June 20, 2011.

${ }^{28}$ Cast, J. and Amatore, D., "NASA Reaches Milestone In Space Launch Initiative Program; Also Announces No SLI Funding for X-33 or X-34,” NASA Release 01-31, March 1, 2001. 
103.

${ }^{29}$ Bond, A., Spaceflight in the Era of Aero-Space Planes, R. J. Hannigan, Krieger Publishing Co., 1994, pp. 102-

${ }^{30}$ Varvill, R. and Bond, A., “ The Skylon Spaceplane: Progress to Realization," Journal of the British Interplanetary Society, Vol. 61, 2008, pp. 412-418.

${ }^{31}$ Reaction Engines Limited, “Appendix B Skylon Upper Stage (SUS)," SKYLON Users' Manual, SKY-RELMA-0001, Rev. 2.1, June 2014.

${ }^{32}$ Varvill, R. and Bond, A., "A Comparison of Propulsion Concepts for SSTO Reusable Launchers," Journal of the British Interplanetary Society, Vol. 56, 2003, pp. 108-117.

${ }^{33}$ Webber, H., Feast, S., and Bond, A., "Heat Exchanger Design in Combined Cycle Engines," IAC-08-C4.5.1.

${ }^{34}$ Varvill, R., "Heat Exchanger Development at Reaction Engines Ltd." Acta Astronautica, Vol. 66, 2010, pp. 1468-1474.

${ }^{35}$ Reaction Engines Ltd., "The Biggest Breakthrough in Propulsion Since the Jet Engine," Press Release, Nov. 28, 2012.

${ }^{36}$ Mehta, U., "Revolutionary Space Transportation Needed," Space News, May 9, 2005.

${ }^{37}$ Mehta, U., "Future of Human Spaceflight," Space News, Aug. 31, 2009.

${ }^{38}$ Barth, T., Eggers, T., Dittrich, R., and Otto, H., "Analysis of the Hypersonic Flow Field Around the Skylon Vehicle," Institute of Aerodynamic and Flow Technology, IB 124-2011/907, Oct. 2011.

${ }^{39}$ European Space Research and Technology Centre, "Skylon Assessment Report," European Space Agency, 2011.

${ }^{40}$ Eggers, T., "Numerical Investigation on the Potential of Steam Cooling for the Skylon Spaceplane in Hypersonic Flow," $28^{\text {th }}$ International Congress of the Aeronautical Sciences, 2012.

${ }^{41}$ Ahmad, A., Maddock, C., Scanlon, T., and Brown, R., "Prediction of the Aerodynamic Performance of ReUsable Single Stage to Orbit Vehicles," Space Access 2011, Paris, Sept. 2011.

${ }^{42}$ Wuilbercq, R., Ahmad, A., Scanlon, T., and Brown, R., "Towards Robust Aero-Thermodynamic Predictions for Re-Usable Single-Stage to Orbit Vehicles," AIAA 2012-5803.

${ }^{43}$ Wuilbercq, R., Pescetelli, F., Minisci, E., and Brown, R., "Influence of Boundary Layer Transition on the Trajectory Optimization of a Reusable Launch Vehicle, AIAA 2014-2362.

${ }^{44}$ Aftosmis, M. J., "Solution Adaptive Cartesian Grid Methods for Aerodynamic Flows with Complex Geometries," Lecture notes, von Karman Institute for Fluid Dynamics, Series: 1997-02, Brussels, Belgium, March 1997.

${ }^{45}$ Aftosmis, M. J., Berger, M. J., and Melton, J. E., "Robust and Efficient Cartesian Mesh Generation for Component-Based Geometry," AIAA Journal, Vol. 36, No. 6, June 1998, pp. 952-960.

${ }^{46}$ van Leer, B., "Flux-Vector Splitting for the Euler Equations," ICASE Report 82-30, Sept. 1982.

${ }^{47}$ Aftosmis, M. J., Berger, M. J., and Adomavicius, G. D., "A Parallel Multilevel Method for Adaptively Refined Cartesian Grids with Embedded Boundaries," AIAA 2000-0808.

${ }^{48}$ Aftosmis, M. J., Berger, M. J., and Murman, S. M., "Applications of Space-Filling-Curves to Cartesian methods in CFD," AIAA 2004-1232.

${ }^{49}$ Berger, M. J., Aftosmis, M. J., and Murman, S. M., "Analysis of Slope Limiters on Irregular Grids," AIAA 2005-0490.

${ }^{50}$ Nemec, M. and Aftosmis, M. J., "Adjoint Sensitivity Computations for an Embedded-Boundary Cartesian Mesh Method," Journal of Computational Physics, Vol. 227, 2008, pp. 2724-2742.

${ }^{51} 1976$ Standard Atmosphere Calculator, http://www.digitaldutch.com/atmoscalc/.

${ }^{52}$ Venditti, D. A. and Darmofal, D. L., "Grid Adaptation for Functional Outputs: Application to TwoDimensional Inviscid Flow,” Journal of Computational Physics, Vol. 176, 2002, pp. 40-69.

${ }^{53}$ Aftosmis, M. J. and Berger, M. J., "Multilevel Error Estimation and Adaptive $h$-Refinement for Cartesian Meshes with Embedded Boundaries," AIAA 2002-0863.

${ }^{54}$ Nemec, M. and Aftosmis, M. J., "Toward Automatic Verification of Goal-Oriented Flow Simulations," NASA/TM-2014-218386.

${ }^{55}$ Pindzola, M., "Jet Simulation in Ground Test Facilities," AGARDograph-79, Nov. 1963.

${ }^{56}$ Brauckmann, G., Greathouse, J., and White, M., "Rocket Plume Scaling for Orion Wind Tunnel Testing," AIAA 2011-3341.

${ }^{57}$ Reaction Engines Limited, SKYLON Users' Manual, SKY-REL-MA-0001, Rev. 2.1, June 2014, p. 6.

${ }^{58}$ Brandis, A., Wray, A., Liu, Y., Schwenke, D., Carbon, D., Huo, W., and Johnston, C., "Validation of HyperRad for Earth Entries," AIAA 2013-2777. 
${ }^{59}$ Gusman, M., Housman J., and Kiris, C., "Best Practices for CFD Simulations of Launch Vehicle Ascent with Plumes - OVERFLOW Perspective," AIAA 2011-1054.

${ }^{60}$ Chase, R. and Tang, M., "The Quest for a Robust, Responsive, Reliable, Efficient and Low Cost Space Access Capability," AIAA 2009-7238. 